University of Windsor

Scholarship at UWindsor

\title{
Upper extremity soft and rigid tissue mass prediction using segment anthropometric measures and DXA
}

\author{
Katherine L. Arthurs \\ University of Windsor
}

Follow this and additional works at: https://scholar.uwindsor.ca/etd

\section{Recommended Citation}

Arthurs, Katherine L., "Upper extremity soft and rigid tissue mass prediction using segment anthropometric measures and DXA" (2007). Electronic Theses and Dissertations. 4709.

https://scholar.uwindsor.ca/etd/4709

This online database contains the full-text of PhD dissertations and Masters' theses of University of Windsor students from 1954 forward. These documents are made available for personal study and research purposes only, in accordance with the Canadian Copyright Act and the Creative Commons license-CC BY-NC-ND (Attribution, Non-Commercial, No Derivative Works). Under this license, works must always be attributed to the copyright holder (original author), cannot be used for any commercial purposes, and may not be altered. Any other use would require the permission of the copyright holder. Students may inquire about withdrawing their dissertation and/or thesis from this database. For additional inquiries, please contact the repository administrator via email (scholarship@uwindsor.ca) or by telephone at 519-253-3000ext. 3208. 
Upper Extremity Soft and Rigid Tissue Mass Prediction using Segment Anthropometric Measures and DXA

by

Katherine L. Arthurs

\begin{abstract}
A Thesis
Submitted to the Faculty of Graduate Studies through the Faculty of Human Kinetics in Partial Fulfillment of the Requirements for the Degree of Master of Human Kinetics at the University of Windsor
\end{abstract}

Windsor, Ontario, Canada

2007

(C2007 Katherine L. Arthurs 


$\begin{array}{ll}\begin{array}{l}\text { Library and } \\ \text { Archives Canada }\end{array} & \begin{array}{l}\text { Bibliothèque et } \\ \text { Archives Canada }\end{array} \\ \begin{array}{l}\text { Published Heritage } \\ \text { Branch }\end{array} & \begin{array}{l}\text { Direction du } \\ \text { Patrimoine de l'édition }\end{array} \\ \begin{array}{l}\text { 395 Wellington Street } \\ \text { Ottawa ON K1A ON4 } \\ \text { Canada }\end{array} & \begin{array}{l}\text { 395, rue Wellington } \\ \text { Ottawa ON K1A ON4 } \\ \text { Canada }\end{array}\end{array}$

Your file Votre référence ISBN: 978-0-494-34974-8 Our file Notre référence ISBN: $978-0-494-34974-8$

NOTICE:

The author has granted a nonexclusive license allowing Library and Archives Canada to reproduce, publish, archive, preserve, conserve, communicate to the public by telecommunication or on the Internet, loan, distribute and sell theses worldwide, for commercial or noncommercial purposes, in microform, paper, electronic and/or any other formats.

The author retains copyright ownership and moral rights in this thesis. Neither the thesis nor substantial extracts from it may be printed or otherwise reproduced without the author's permission.
AVIS:

L'auteur a accordé une licence non exclusive permettant à la Bibliothèque et Archives Canada de reproduire, publier, archiver, sauvegarder, conserver, transmettre au public par télécommunication ou par l'Internet, prêter, distribuer et vendre des thèses partout dans le monde, à des fins commerciales ou autres, sur support microforme, papier, électronique et/ou autres formats.

L'auteur conserve la propriété du droit d'auteur et des droits moraux qui protège cette thèse. $\mathrm{Ni}$ la thèse ni des extraits substantiels de celle-ci ne doivent être imprimés ou autrement reproduits sans son autorisation.
In compliance with the Canadian

Privacy Act some supporting forms may have been removed from this thesis.

While these forms may be included in the document page count, their removal does not represent any loss of content from the thesis.
Conformément à la loi canadienne sur la protection de la vie privée, quelques formulaires secondaires ont été enlevés de cette thèse.

Bien que ces formulaires aient inclus dans la pagination, il n'y aura aucun contenu manquant. 


\begin{abstract}
Katherine L. Arthurs

University of Windsor

\section{Upper Extremity Soft and Rigid Tissue Mass Prediction using Segment Anthropometric Measures and DXA}

Multiple linear stepwise regression was used to generate equations to predict bone mineral content (BMC), fat mass (FM), lean mass (LM), and wobbling mass (WM) of three segments of the upper extremities including the arm, forearm, and forearm + hand segments using simple anthropometrics. Full body scans using Dual Energy X-ray Absorptiometry (DXA) were used as the reference method. $100(50 \mathrm{M}, 50 \mathrm{~F})$ young adults, ranging in age from 17 to 30 years, volunteered where data from 76 participants was used to generate the equations while data from the remaining 24 was used for equation validation. Prediction equations exhibited high adjusted $\mathrm{R}^{2}$ values (range from 0.854 to 0.968 ). Scatter plots of the actual versus predicted masses of the validation group revealed a close relationship $\left(\mathrm{R}^{2}\right.$ range from 0.681 to 0.951$)$. This indicates that accurate estimates of in-vivo tissue masses for upper extremity segments can be predicted by anthropometrics. 


\section{Dedication}

This thesis is dedicated to my parents, Jake and Marlene Teigrob.

Your love, support, and constant encouragement have motivated me, allowing this to be possible. I cannot express my love and gratitude enough. 


\section{Acknowledgements}

I would first like to extend a much deserved thank you to my advisor, Dr. David Andrews, without whom this thesis would not have been possible. You not only dedicated yourself to aiding me in the successful competition of this paper but you invested your time, support, and encouragement into mentoring me both within the realm of research and without. I cannot tell you how much I have come to appreciate your guidance. Your passion and commitment to both your work and family have truly been an inspiration.

To my thesis committee members, Dr. Wayne Marino and Dr. Maher El-Masri, I would like to acknowledge you and thank you for the time that you have invested in supporting me, for contributing to my knowledge in the subject area, and providing guidance towards a successful methodology and analysis. I have come to really respect and appreciate you both. I would especially like to thank Dr. Marino; you have had a positive influence on me even throughout my undergraduate studies. Your knowledge and passion for biomechanics have, in part, led me here, following a biomechanics related interest.

Thank you to NSERC for providing funding for this project, without which access to the necessary equipment for data collection would not have been possible.

Thank you to Windsor Regional Hospital, Metropolitan Campus, for your cooperation and technical support regarding data collection and DXA scanning. Karen Anderson, from the research ethics office, Ralph Nicoletti, Director of Diagnostic Services, Catherine Bonnett, Manager of Nuclear Medicine, and all the technologists, you were a great help in making this process a smooth one. 
Data collection would not have been possible on my own. I would like to thank Tim Burkhart, Girish Sankar, and Paula van Wyk for the time and effort they lent in the data collection process. To Tim and Girish, who were responsible for collecting the anthropometric data of each of the participants, I know that sometimes the days seemed long and it was not easy but please know how much I appreciated being able to entrust you with this task. To Paula, it would not have been possible to collect data from the participants if they were not at the hospital; as a result your taxi services were invaluable.

To my fellow grad students and lab mates, thank so much for listening to my frustrations and providing a constant source of encouragement and help through tough and stressful times. Paula and Chrim, you became strong allies through grad school with your crazy antics and welcome friendships. You have definitely contributed to making this experience a positive one.

Finally, I wish to thank my husband, Bryan. Not only have you been a never ending source of support and encouragement to me throughout grad school, and especially my thesis, you have volunteered your own time to participate in various studies to help me along the way. Thank you for motivating me and challenging me to do the best that I can. I am so fortunate to have such wonderful support at home, I hope you know how much I love and appreciate you. This thesis would not be a completed success without you. 


\section{TABLE OF CONTENTS}

$\begin{array}{lrr}\text { ABSTRACT } & & \text { III } \\ \text { DEDICATION } & & \text { IV } \\ \text { ACKNOWLEDGEMENTS } & \text { V } \\ \text { LIST OF TABLES } & & \text { VIII } \\ \text { LIST OF FIGURES } & & \text { IX } \\ \text { GLOSSARY } & & \text { X } \\ & & 1 \\ & \text { I. INTRODUCTION } & 6 \\ & \text { II. REVIEW OF LITERATURE } & 6 \\ & \text { Biomechanical Models } & 8 \\ & \text { Upper Limb Injuries } & 10 \\ & \text { Methods of Body Composition Quantification } & 34 \\ & \text { METHODS } & 34 \\ & \text { Participants } & 35 \\ \text { Instrumentation } & 36 \\ & \text { Procedures } & 39 \\ & \text { DXA Analysis } & 42 \\ \text { Statistical Analyses } & 49 \\ & \text { RESULTS } & 49 \\ & \text { Initial Results } & 52 \\ & \text { Prediction Equation Generation } & 54 \\ \text { Prediction Equation Validation } & 59 \\ & \text { VISCUSSION } & 59 \\ & \text { Summary of Results } & 59 \\ \text { Comparison to the Literature } & 63 \\ & \text { Potential Error Sources } & 69 \\ & \text { Prediction Error } & 70 \\ & \text { Functional Significance and Application } & 71 \\ \text { Limitations } & 73 \\ & \text { Future Directions } & 74 \\ & \text { Appendix } & 78 \\ & \text { References } & 87\end{array}$




\section{LIST OF TABLES}

Table 1: Description of upper extremity measurements taken bilaterally and recorded to the nearest millimetre, where (M-L) and (A-P) indicate that the measurements was taken in the medial-lateral and anterior-posterior directions, respectively.

Table 2: Mean $( \pm S D)$ scores of the general physical characteristics and anthropometric measures for male and female participants in both sample groups.

Table 3: Prediction equations for BMC, FM, LM, and WM tissues of the arm, forearm, and forearm + hand segments.

Table 4: Mean $( \pm \mathrm{SD})$ predicted and actual masses (DXA) and mass error for the validation sample $(n=24)$.

Table 5: Comparison of explained variance $\left(\mathrm{R}^{2}\right)$ and standard errors (SEE) for each of the tissue mass segments between the current study and that of Holmes et al. (2005) for the lower extremities.

Table 6: A comparison of predicted body composition across studies using $\mathrm{R}^{2}$ and SEE (g) values.

Table A1: Description of lower extremity measurements taken bilaterally and recorded to the nearest millimetre, where (M-L) and (A-P) indicates that the measurements were taken in the medial-lateral and anterior-posterior directions, respectively. These measurements are identical to those used by Holmes et al. (2005).

Table A2: Mean (SD) measurements for the upper extremity by site ( $\mathrm{cm}$ ), measurement differences between and within-measurers $(\mathrm{cm})$, and between and within-measurer reliability coefficients (ICCs). Significant differences $(\mathrm{p}<0.05)$ between-measurers and between sexes are indicated with a $*$ and $\uparrow$, respectively (Burkhart et al., 2007). 


\section{LIST OF FIGURES}

Figure 1: Region of interest selected from enCORE software including the arm, segmenting around the humeral head and at the elbow

Figure 2: A. segmentation at the shoulder joint, B. segmentation at the elbow joint, and C. segmentation at the wrist. The dashed lines represent Dempster's segmenting technique (1955) and the solid black line represents the technique by Clarys et al. (1984) (figures are from Clarys \& Marfell-Jones, 1986).

Figure A1: Research Ethics Board approval from the University of Windsor 


\section{GLOSSARY}

2-C A 2-component model is a method of in vivo (see below) body composition estimation where values for fat content are generated through the assessment of two of the body's components, usually fat and fat-free masses.

4-C A 4-component model is a method of in vivo body composition estimation which incorporates the analysis of four different body components. Fat is then calculated with the use of pre-generated formulas.

BMC Bone Mineral Content refers to the make up of the bone. For example, it accounts for bone calcium, and relates to bone density and strength.

CT Computerized Tomography, a type of imaging technology utilizing rotating x-ray tubes and film to produce cross-sectional tissue images for diagnostic and body composition tissue analyses.

DV Dependent variable, a value that is affected or determined by another factor or value. For this study the dependent variables consisted of the tissue masses for each of the segments.

DXA Dual Energy X-ray Absorptiometry is an imaging technology which uses photon rays to measure soft and rigid tissues based on their density. A useful tool in medical and research fields for bone density and body composition analysis.

FM Fat Mass, the masses of the body made up of fatty tissues.

FFM Fat Free Mass includes the mass of all the tissues in the body that are not fat.

In Vivo Reference to the living population.

In Vitro Reference to post-mortem population.

IV Independent variable, a value that is unchanged when compared to others or used to determine or predict others. The independent variables of this study consisted of the anthropometric measurements and other predictor variables.

$\mathrm{K}$ Counting Potassium counting is a method of body composition analysis where fat may be estimated by the amount of potassium found in the body, since it is assumed that potassium only exists in lean tissue.

LM Lean mass refers to soft tissue mass in the body that is not fat. This is mostly composed of muscle tissue but also includes tendons and ligaments. 
mRem milli-roentgen-equivalent man, unit of radiation dose

MRI Magnetic Resonance Imaging allows for high resolution view of soft tissues from detectors mapping out the targeted tissues as they respond to a $360^{\circ}$ magnetic field and radiation waves.

Rigid mass Musculoskeletal tissue in the body that is not soft, mainly bone.

ROI Regions of interest are specific regions of the body that are targeted for analysis. This term is used in reference to specified segments for body composition analysis using the DXA software.

SEE Standard Error of the Estimate, a measure, in grams, of the degree of error for the prediction equations.

Segmentation A method of separating body parts from the rest of the body for independent body composition analysis.

Soft Tissue Soft Tissue refers to the fat and lean mass components of the body.

WM Wobbling mass encompasses all the non-rigid parts of the body, including soft tissues such as fat, muscle tissue, internal organs, as well as bodily fluids. 


\section{INTRODUCTION}

Biomechanics focuses on studying internal and external forces on the body, often by way of biomechanical modeling. Biomechanical models function to illustrate the mechanics of a living body and how it responds to different variables (i.e. force). These models are important tools for answering questions about human capacities, injury prevention, as well as static and dynamic assessments relating to ergonomics and athletics, among other things. Such models are developed to simplify the complex system of the human body and acquire specific information pertaining to that system.

The mechanical system of the human body is made up of rigid (bones) and nonrigid (muscles and other soft tissues) masses, which are attached to each other via connective tissues (Liu \& Nigg, 2000). These masses respond differently to internal and external forces placed on them, which affect the way the body will respond in different scenarios. The differential motion of the soft and rigid tissues has been found to play a significant role in the body's response to impact loading (Gittoes, Brewin, \& Kerwin, 2006).

Biomechanical modeling has traditionally used rigid link segments to estimate internal joint forces (Farley \& Gonzalez, 1996; Ferris \& Farley, 1997). However, this type of modeling does not result in representative values of the human during impact because it does not account for soft tissue motion that occurs relative to bone (Gruber, Ruder, Denoth, \& Schneider, 1998). The increase of research in this area over the last ten years has lead to the coining of the phrase "wobbling mass" (WM), which encompasses all the non-rigid parts of the body, including soft tissues such as fat, muscle tissue, internal organs, as well as bodily fluids (Yue \& Mester, 2002). 
Studies that have examined the effects of WM have reported that soft tissue mass and rigid-body mass react differently in many situations (Yue \& Mester, 2002). In fact, soft tissue masses have been found to greatly influence the magnitude of transmitted forces through body segments (Gruber et al., 1998). More specifically, Pain and Challis (2006) reported that joint torques and forces calculated in their WM model were lower than those of a rigid-body model and accentuate the importance of determining the effects of soft tissue motion during impacts. As a result of such findings, it has been suggested that a model of the human body using rigid segments alone is only justified for studying slow quasi-static movements and is particularly not appropriate when studying impact situations (Liu \& Nigg, 2000).

A specific challenge to biomechanists who want to incorporate wobbling tissues into biomechanical models has been the quantification of body tissue masses in living people. Body composition quantification methods can therefore aid in answering questions of how and why our bodies physically respond the way they do. It is a reasonable challenge since accurate quantification involves precise measurement of the components that make-up the body.

Much of the data available on human body composition have come from cadaver segmentation studies and even these are limited (Clarys, Martin, Marfell-Jones, Janssens, Caboor, \& Drinkwater, 1999). Data attained from cadavric research may be useful, but it must be interpreted and used with caution since cadavers are often embalmed and frozen then thawed for data collection which, some studies have shown, can affect the structural and mechanical properties of the tissue (Callaghan \& McGill, 1995). Other limitations of in vitro research include: segmentation and dissection differences between investigators, the effects of cadaver fluid loss, the limited number of studies conducted for body 
composition quantification, accompanied by the small number of specimens used for these studies, and also the complication of applying in vitro data to a living population. Further, there has been a lack of in vivo research done to validate such data (Clarys et al., 1999), leaving a specific need for in vivo research focussed on the quantification of WM in segments such as those in the upper and lower limbs.

Modern imaging technologies have allowed researchers to analyze tissues beneath the skin in living people. These methods have been developed to specifically assess rigid tissues, soft tissues, or both. As energy passes through the body, investigators are able to obtain measures of the body without having to use invasive methods. Through the use of modern imaging technology, segmenting techniques may also be applied to current in vivo studies. Holmes, Andrews, Durkin, and Dowling (2005) used anthropometric measurements to create regression equations to predict in vivo soft tissue masses of the lower limbs. They used Dual Energy X-ray Absorptiometry (DXA), which has the capacity to measure both rigid and soft tissue masses, to validate these predictions by specifically segmenting the lower extremities using DXA software. They were the first to develop working equations for the estimation of soft tissue masses in living people in this manner. These equations save researchers both the time and money that would otherwise need to be spent on technologies such as DXA. However, this work is limited in terms of the number of people that were scanned and because it only considered the lower extremities.

The literature reflects growing attention paid to musculoskeletal injuries of the upper extremities. Researchers are increasingly concerned with upper limb injuries that occur during work (e.g. Potvin, Chiang, Mckean, \& Stephens, 2000), recreational activities (Sherker \& Cassell, 1999; Made \& Elmqvist, 2004), and as a result of falling 
with outstretched arms (e.g. Hsiao \& Robinovitch, 1998). In light of the increase in upper limb musculoskeletal disorders incurred during these types of activities, it is important to understand the mechanisms of injury in order to decrease or even prevent their occurrence. This understanding depends on having accurate upper extremity biomechanical models which account for WM contributions. However, before these types of models can be developed, accurate estimates of in vivo soft tissue masses for the upper limbs must be made available.

The availability of soft tissue masses for the upper extremities of living people is not available in part because of the cost associated with the use of the necessary scanning equipment. This high cost is also reflected in the low number of appropriate scanners available for use. In addition to this, there would be a large time commitment to any researcher interested in gaining such data since a large sample group would be required to ensure the accurate representation of the population. If a method could be developed to easily predict specific tissue masses of the upper extremities the cost and time necessary for obtaining the data would be significantly decreased. In lieu of this, such data may become more readily available and lend itself not only for use in biomechanical modelling that accounts for WM, but could also be used to predict tissue masses of any interested party, including athletes and those with health and body composition related concerns.

Purpose

The purpose of this study was to create tissue mass prediction equations for the upper extremities, similar to the ones created by Holmes et al. (2005) for the lower extremities, which allow for the estimation of in vivo bone mass (BMC), fat mass (FM), 
lean mass $(\mathrm{LM})$ and wobbling mass $(\mathrm{WM}=\mathrm{LM}+\mathrm{FM})$ from simple segmental anthropometric measures. Separate equations were created for three segments of the upper extremity including the arm, forearm, and the forearm and hand segments. DXA scans were used to provide the actual tissue masses for purposes of developing and validating the equations. 


\section{REVIEW OF LITERATURE}

Biomechanical Models

Background

Biomechanical models have been developed as simplified versions of the human body for the purpose of better understanding the body and the way it responds to different stimuli. Traditionally, biomechanists have used rigid segment modeling to simulate and analyze movement activities such as running and hopping (Farley \& Gonzalez, 1996; Ferris \& Farley, 1997). True to their name, this form of modeling consists of a system of connected, rigid segments representing in vivo segments. Segment connections are sometimes represented by a series of springs and dampers in order to simulate human movement (Liu \& Nigg, 2000; Pain \& Challis, 2004).

These types of models have been useful analysis tools, allowing further investigation into the complexity of human motion. However, it is apparent that rigid segment modeling is too simplistic in some dynamic situations (e.g. impact). Since spring and damper systems, or other methods of rigid segment connection are typically constant throughout the model, they do not account for neuro-muscular regulation (Liu \& Nigg, 2000), nor do they account for rapid changes in joint angles or muscle activity following the impact (Bobbert, Yeadon, \& Nigg, 1992). These inaccuracies inherent in rigid segment modeling have led researchers to explore other, more realistic forms of human modeling. However, resistance to develop or use a model that would consider these elements is met because it would mean a great increase in the complexity of the model. Pseudo-rigid body models have been developed which include some elements of increased complexity (Midah, Howell, \& Norton, 2000) but, more ideally, models including wobbling masses have been developed and are now being used more and more 
frequently in research (Gruber et al., 1998; Liu \& Nigg, 2000; Pain \& Challis, 2002;

Gittoes et al., 2006).

\section{Wobbling Mass Models}

Wobbling mass (WM) models incorporate both soft and rigid masses of the body into a more complete system and model structure. They contain rigid segments with soft tissue masses attached to them by viscoelastic tissue connections. This allows the WM to oscillate around the segments' rigid mass centres (Gittoes et al., 2006; Pain \& Challis, 2006). It is important that WM models include this functional ability since it has been found that human WM can be displaced relative to the bone (Gruber et al., 1998). This happens frequently in dynamic situations and is important since the movement of the WM has been shown to have a significant effect on in vivo attenuation of force in dynamic, especially impact, situations. Soft tissue movement can account for observed decreases in joint moments (Gruber et al., 1998; Yue \& Mester, 2002).

WM models have been developed largely to realistically replicate the response of the human body to impact loads (Gruber et al., 1998). Particular focus has been placed on the lower extremities, specifically impact loading of the heel (Gruber et al., 1998; Pain \& Challis 2004, 2006) and the effects of rigid and WM distribution on load attenuation (Liu \& Nigg, 2000). Although similar work has not been completed for the upper extremity, valuable information has been gained from these lower extremity studies that may be applied. For example, soft tissue properties have been found to play an important role in shock attenuation in the leg following heel impact (Gittoes et al., 2006; Pain \& Challis, 2006). It is reasonable to assume that the soft tissues of the palm would have similar effects on the upper extremity during impacts to outstretched hands, such as 
would occur during falls. As stated earlier, the largest hurdle for researchers concerning WM models is accounting for the added complexity associated with all the tissues. If wobbling mass tissue magnitudes could be predicted with simple anthropometric measurements, this would significantly decrease the effort, time and money that would be required to develop a WM model of the upper extremities.

\section{Upper Limb Injuries}

\section{$\underline{\text { Recreation and Falls }}$}

Upper extremity injuries are becoming more and more prevalent with the increase of sports such as in-line skating and snowboarding (Sherker \& Cassell, 1999; Made \& Elmqvist, 2004). Injuries related to these sports are a result of falling and impact bracing, at high velocities. Despite decreased velocities during walking, this is the most common mechanism of many upper limb injuries of the elbow and the wrist in both the young and elderly (Amis \& Miller, 1995; Hsiao \& Robinovitch, 1998). These falls often occur in a backwards direction, and have been found to have high impact velocities at the hand and wrist, leading to a high injury rate (Tan, Eng, Robinovitch \& Warnick, 2006).

Snowboarders, especially beginners, have a tendency to fall frequently, both forwards and backwards, and since the rider's legs are anchored to the board they are not able to step out to correct imbalance. Therefore, as they are falling, their arms and hands are their only defence against the ground (Made \& Elmqvist, 2004). For snowboarders, the most common diagnoses for injury are lower arm/wrist fractures (20\%), and lower arm sprains (12\%) (Made \& Elmqvist, 2004). In sports such as this and in-line skating, soft tissue injuries occur in addition to possible damage to the bone (Sherker \& Cassell, 1999). 


\section{Occupational Injuries}

Upper limb injuries, due to impact, may also be incurred at work. It is not uncommon to have manufacturing assembly tasks that involve repetitive hand impacts (Potvin et al., 2000). For example, in door trim panel installation in the automotive industry, the base of the hand is used as a hammer to force the plastic push pins of the trim into the metal frame to seat the panel (Potvin et al., 2000). Even if the impact velocities of this type of work do not reach those of a fall, the repetition is sufficient to put the worker at significant risk of injury for developing disorders such as hand arm vibration syndrome. In addition to the trauma placed on the body as a result of repeated impacts, employees are often required to be in awkward positions while completing these tasks, putting themselves at further risk of fracture and/or soft tissue injury.

\section{Summary}

The high incidence of upper extremity musculoskeletal disorders incurred as a result of daily activities (work and recreation) is further evidence of the need for biomechanical assessment of in vivo upper limbs. This could provide great insight into how such injuries occur and how they may be prevented. Quantification of the masses that comprise the upper extremities is an important step towards understanding their responses. If body composition prediction equations were available, inputs for WM models could be attained through the use of simple anthropometry. WM models simulating upper limb impacts could then provide investigators with specific knowledge of how individual tissues respond in a given situation, thereby providing insight into why and when upper limb injury may occur. 
Methods of Body Composition Quantification

In order to learn and understand the make-up and function of the human body, early researchers turned to cadaver dissection. This form of investigation allowed for sub-epidermal levels of observation and separation of deep tissues, which is not feasible in living people. Direct evaluation of living people is appealing compared to cadaveric work because it is more time efficient, living people are more readily available than cadavers, and it reduces the amount of error that may be incurred as a result of applying in vitro research results to the living population. Traditional methods of estimating in vivo body composition, which are relatively inexpensive and easy to use, include techniques such as anthropometry, total body water, and bioelectrical impedance. Every method of body composition estimation has advantages and limitations. Since no method is free of error, they are often used to validate each other (Martin, Daniel, Clarys, \& Marfell-Jones, 2003). Recent technologies have also made it possible to take direct in vivo measurements of deep body tissues for use in research and medical diagnosis. These imaging technologies include, but are not limited to: magnetic resonance imaging (MRI), computed tomography (CT), and dual energy x-ray absorptiometry (DXA).

\section{In Vitro Methods of Body Composition Quantification}

By the end of the nineteenth century anatomical mass data were based on only nine dissections, and only muscle and body masses were reported (Martin, Spenst, Drinkwater, \& Clarys, 1989). A series of questions concerning muscle mass in relation to athletics, nutrition, and gravity deprived environments, lead to more in depth investigations (Martin et al., 1989). With the increased interest in body composition by means of in vitro dissection, methods were developed for tissue separation and 
segmentation, in order to quantify soft tissue masses of specific body parts individually. There is no simple way of segmenting the human body geometrically (Grand, 1977). Therefore, various methods have been derived whereby most of the differences between them are centered around the selection of the cutting plane when separating body parts (Clarys \& Marfell-Jones, 1994). Three main methods have been developed for cadaver segmentation.

\section{Three Methods of Anatomical Segmentation}

The first method allows for the segmentation of body parts by sawing across the joint centres of frozen cadavers that separate the targeted segment(s) (Braune \& Fischer, 1889; Dempster, 1955). This may result in the division of a bone as well as soft tissues into two different segments (Figure 2: see Methods). For example, when segmenting the leg from the thigh at the knee, the cutting plane will divide the femoral condyles and patella so that the distal portions will be segmented with the calf, while the remaining, proximal portions will be incorporated with the thigh segment. This type of unidirectional segmentation was justified because it was seen as essential for biomechanical analysis. Despite the perceived necessity of the uni-directional segmentation, the idea of the joint centre cutting plane raised some questions and concerns as to the allocation of bone portions that were separated as a result (Clarys \& Marfell-Jones, 1994).

The second segmentation method, developed by Grand (1977), took on a slightly more complex methodology than that of Braune and Fischer. This method involves the separation of individual muscles at their origins and insertions through the cutting of tendons. Following this separation, the entirety of each muscle is assigned to one of the bordering segments on either side of the joint. The muscle is generally attributed to the 
segment containing the majority of that muscle's mass. For example, segmentation about the knee joint would attribute the thigh with the biceps femoris and medial knee flexors while the leg segment would claim the patella along with the long muscles of the region. Grand segmented in this fashion so that the intact muscle groups of one dissection could be compared, in corresponding segments, to another specimen (Grand, 1977).

The third segmenting technique was developed as a compromise between the two existing methods in order to insure maximum usability of dissection data while not sectioning any bones. In 1984, Clarys, Martin, and Drinkwater segmented both fresh and embalmed cadavers by severing the segment at the joint space (similar to the method used by Braune and Fischer, and Dempster), in the general plane of the proximal articulating surface. However, rather than segmenting the bone, as performed in the first method, Clarys and colleagues chose to circumvent any bony parts where they protruded across the plane of the cut (Figure 1). This would allow bone ends to remain intact with the appropriate segment, similar to Grand's approach.

\section{Limitations of In Vitro Research}

Until the 1980s, most of the cadaver research performed in this area quantified the mass of total segments, but not the internal composition of those segments (Clarys \& Marfell-Jones, 1994), or noted the composition masses but not the total body masses (Clarys et al., 1999). Another unfortunate downfall of cadaver research is the lack of direct methods for fat estimation (Clarys, et al., 1999). Direct methods of in vitro investigation have been used to measure fat, but use of these direct methods for validation of in vivo fat estimation techniques has been predominantly ignored. 
Despite the leading role that cadavers have played in body composition research, there have been relatively few studies performed to investigate this matter. Further, many of the studies performed have obtained data from only a small number of specimens (Dempster, 1955; Clarys et al., 1999). As a result, the data collected from these small populations may not be an accurate representation of the larger population (Holmes et al., 2005).

One of the largest challenges of segmentation for the purpose of body composition quantification is the sensitivity of the data with respect to the method of segmentation. Significantly different results between studies are likely if different researchers use different methods of segmentation. Therefore, body composition data can not be directly compared between studies unless the same segmentation methods have been accurately followed. Instead, the data must be interpreted with the idiosyncrasies of the investigator's data gathering techniques (Dempster \& Gaughran, 1955).

There is a need for dissections which include in vivo methods for the purpose of validation. Without such studies, research will continue by way of comparing several indirect methods of evaluation, but true conclusions will be unreachable (Clarys et al., 1999). Mathematical models have been developed by Hanavan (1964) to help overcome the limitations with the application of cadaver research to the living. These models are not frequently used though because they assume that the body has a uniform density throughout, which is potentially a major source of error (Clarys \& Marfell-Jones, 1986).

\section{Frozen/Embalmed verses Fresh Cadavers}

In vitro specimens may be compromised due to post-mortem effects such as changes in tissue properties and mechanics. Little research has been conducted in this 
area, however, it has been found that bioelectrical impedance of a lateral abdominal skinfold in rats increases exponentially in the first 120 hours after death (Querido, 1998). This signals that some changes do occur in the body after death that could potentially affect body mass composition research. It is not known what causes this or whether or not this phenomenon occurs in humans. However, it is important to bear in mind that post-mortem changes may exist and have effects on collected tissue mass data, which in turn, should be used and interpreted cautiously.

Consideration should also be given to the condition of the specimen for dissection. Many cadavers are frozen and/or embalmed prior to dissection. It has been shown that structural properties of porcine vertebrae are altered as a result of frozen storage (Callaghan \& McGill, 1995). The properties of other tissues have not been investigated, but as a result of the unknown and the potential effects on body composition and its quantification, it is necessary to realize the potential for error here. Despite this, the problems typically experienced during a fresh/frozen cadaver dissection are related to bodily fluid loss. Grand (1977) went as far as to say that fluid loss occurs as a part of every dissection, in muscle more than bone. Clarys, Martin, and Drinkwater (1984) found a two kilogram weight loss of their specimen and attributed it to evaporation from the moist tissues which were exposed during dissection. The discrepancies caused by the fluid evaporation, in most cases, have not been found to significantly affect body composition measurements.

Some methods typically used to decrease evaporative weight loss during dissection include storing the specimen in humidified areas and embalming the specimen prior to dissection. It has been found that embalming an in vitro subject (with embalming fluid) may restore hydration to a morphology more representative of the living state 
(Todd \& Lindala, 1928). However, despite the advantages embalming has regarding body fluid evaporation, it is not without its disadvantages. To correctly preserve a cadaver via embalming about 6 litres of embalming fluid must be injected either into the left femoral artery or the carotid artery (Clarys et al., 1984). Body composition inaccuracies may be introduced if this fluid is not evenly distributed. Clarys and colleagues (1984) found that fat, muscle, and undifferentiated tissues retained more of the embalming fluid than the bone or skin. As a result, increased weights and anthropometric measurements of the specified tissues were increased in comparison to the skin and bone.

\section{In Vivo Methods of Body Composition Quantification}

Segmentation and body tissue separation are ideal for determining body composition of cadavers. Since direct measurements can not be made in vivo, several methods have been developed for body composition estimation. These models vary in level of complexity, accuracy, and availability. The most commonly used traditional methods include: multi-component models such as hydrostatic weighing, total body water, bioelectrical impedance, potassium counting, and anthropometry. A general description of each method is outlined below.

\section{Multi-component Models}

Multi-component models are a means of estimating body composition by accounting for a number of the body's components or compartments together. Multicomponent models are typically either comprised of two components or four components. A limitation of using this type of model to estimate body composition is that any errors or 
inaccuracy incurred during the measurement of one component, or more, may compound and compromise the combined results (Lohman \& Going, 1993).

\section{2-Component Model (2-C)}

2-C models are designed to provide body composition analysis based on two of the body's components. The components most often used for this type of analysis are the fat and fat-free mass (FFM) components. The premise behind the 2-C model is that if the FFM of the body can be determined, than body fat can be found indirectly as the difference between the body weight of the participant and their FFM (Ellis, 2000). Body density has been used as a 2-C model. In fact, hydrodensiometry has been used as a reference method for body composition for a long time (Kohrt, 1998). Nuclear-based methods also exist as 2-C models, such as potassium counting (Ellis, 2000).

\section{Hydrostatic Weighing}

Hydrostatic weighing or hydrodensiometry is a method of measurement whereby the participant sits on a chair, completely submerged in water, and exhales as much as they can. Body volume is calculated by a measurement of water displacement while underwater weight can be gained digitally since the chair can be suspended from load cells (Wellens, Chumlea, Guo, Roche, Reo, \& Siervogel, 1994). Prior to submersion, residual lung volume is assessed by helium dilution, allowing the body volume from displacement to be consequently adjusted (Visser, Fuerst, Lang, Salamone, \& Harris, 1999; Salamone et al., 2000). In order to decrease methodological error and lend to participant comfort, the water temperature is usually maintained from $32-35^{\circ} \mathrm{C}$ and 
participants are asked to wear bathing suits. Also to ensure reliable data, multiple submersions are performed, and the average of the most consistent trials is usually taken (Visser et al., 1999; Salamone et al., 2000).

This 2-C model has been used as the gold standard in the past, but with recent advances in depth imaging technologies, it is being used less frequently of late. One of the drawbacks that may contribute to its decrease in popularity may be how difficult the task is for participants to perform (Kohrt, 1998). Despite investigators' efforts to make subjects as comfortable as possible, the subjects are still required to submerge themselves a number of times while exhaling and trying to sit on a chair underwater. Another limitation is the assumption that the ratio of FFM components (water, protein, and minerals) is unchanging across varying demographics. This is not true of the human body and assuming so may result in less accurate results for some populations, particularly children and the elderly (Kohrt, 1998). The biggest problem though with using hydrodensiometry as a means of body composition estimation is in deriving percent body fat, which involves converting density to fatness (Ball, Altena, \& Swan, 2004).

\section{Potassium Counting}

Potassium counting ( $\mathrm{K}$ counting) is a procedure that has been developed for the estimation of whole body lean tissue. This works on the theoretical basis that the naturally occurring $\mathrm{K}$ in the body exists in the body's FFM (Wang, Zhu, Wang, Pierson, \& Heymsfield, 2003). This $\mathrm{K}$ may be measured with a gamma ray and two sodium iodide detectors which are often placed just above and below the xiphoid process (Grinspoon et al., 1996; 1998). The $\mathrm{K}$ is counted at each of these detectors with a body scintillation counter (Haarbo, Gotfredsen, Hassager, \& Christiansen, 1991). Counted K may be 
related to the lean body mass at a rate of $2.5 \mathrm{~g} \mathrm{~K} / \mathrm{kg}$ lean body mass (Grinspoon et al., 1996). However, in order to allow measured potassium in the body to yield FFM estimates, studies have been done to determine total body potassium to FFM ratios for men and women independently, and provide necessary formulae for each (Forbes, 1987). There are disadvantages of total body $\mathrm{K}$ counting for both researcher and participant. For the researcher, facilities to perform such investigations are limited and potentially difficult to obtain. For the participant, this procedure has been found to be somewhat claustrophobic which may lead to subject recruitment limitations (Haarbo et al., 1991).

\section{4-Component Model (4-C)}

A 4-C model can be any model incorporating four different components. Prior and colleagues (1997) suggest that the assessment include: fat, water, mineral, and protein (residual) compartments. This would account for fluctuation of water, minerals and FFM density within the participant. However, it has also been suggested that the four components used for body composition assessment would best include: body density, total body water, total bone mineral mass, and body weight (Visser, et al., 1999;

Salamone et al., 2000). The compartmental data collected from each of these components would then be inserted into a formula derived by Lohman and Going (1993) in order to determine percent body fat. As a result, FFM may also be obtained by subtracting this value from the participant's body weight (Visser et al., 1999).

The body density required for this formula may be collected via hydrostatic weighing (Salamone et al., 2000; Visser et al., 1999). In order to gather data pertaining to the total body bone mineral mass, DXA imaging can be utilized (Salamone et al., 2000). Whereas DXA assumes constant body water, the 4-C model allows a more individually 
accurate assessment since it does account for individual differences in water content and the mineral content of the FFM (Visser et al., 1999).

Along with modern imaging technologies this 4-C model has been used more and more. However, one issue that needs be considered is the use of hydrostatic weighing for determining FM because it introduces the limitations of this method, such as the density to fat conversion. Another limitation of the 4-C model is that it is not convenient or even realistic to gather data for all four components on a large group of subjects.

\section{Total Body Water}

Water molecules are made up of one oxygen and two hydrogen atoms. This method of calculating total body water as an assessment of body composition is based on the premise that the hydrogen atoms can be exchanged with isotopic water, substituting the hydrogen with deuterium (Culebras \& Moore, 1977). A known dose of deuterium oxide of about $4.0 \mathrm{~g}$ diluted in about $50 \mathrm{ml}$ of water can be ingested orally by the participant (Salamone et al., 2000), or injected (Culebras \& Moore, 1977). After the deuterium has entered the body some time must be given to allow the deuterium oxide to equilibrate with the water, with the assumption that the distribution of volume of the isotope and the mode of exchange are similar to those of water. This enables the possibility of calculating total body water and deriving FFM (Wellens et al., 1994) by using the equilibrium concentration as the denominator (Culebras \& Moore, 1977). This information is obtained by a comparison of blood (Salamone et al., 2000), saliva (Wellens, 1994), or other bodily fluids, taken before the deuterium was given, and two to five hours after (Wellens, 1994; Salamone et al., 2000). A high-resolution mass spectrometer can be used to detect the deuterium oxide (Wellens, 1994; Salamone et al., 
2000). Corrections need to be made in the case that the deuterium oxide entered an exchange with hydrogen atoms not of a water molecule (Culebras \& Moore, 1977; Wellens et al., 1994; Salamone et al., 2000). It has been found that without correction this method can overestimate total body water by up to $5 \%$ (Culebras \& Moore, 1977). Salamone and colleagues (2000) corrected their sample by dividing the deuterium. dilution space (litres) by 1.041 . These results have been found to show high correlation with body weight (Culebras \& Moore, 1977).

\section{Bioelectrical Impedance}

Bioelectrical impedance analysis measures the body's resistance of an applied alternating current (Lukaski, Johnson, Bolonchuck, \& Lykken, 1985). Since water contains dissolved electrolytes it is able to conduct the current while other body components are unable to (Chumlea, \& Guo, 1994; Van Marken Lichtenbelt, Westerterp, Wouters, \& Luijendijk, 1994). As a result, the resistance of the current can translate to total body water (Deurenbuerg, 1996). This technique is based on the theory that the body's ionic circuit is set up like a series circuit (Kotler, Burastero, Wang, \& Pierson, 1996). However, this is not a certainty and may be an inherent error of this method. Further, this model is based on the assumption that the body is cylindrically shaped, which is not the case (Kotler, et al., 1996). Another assumption used for bioelectrical impedance analysis is that the hydration is constant (Deurenberg, 1996). However, hydration varies between subjects, which may result in over or underestimation of fat and/or FFM. For example, if there is a decrease in bodily hydration an impedance increase will result (Deurenberg, 1996). Differences have also been found between very lean individuals and those who are obese. Research has shown that large errors may exist 
in the predicted body fat percentages for very lean subjects even to the point where the FFM may be found to be larger than the subject's actual body weight. For obese participants, it was found that impedance underestimated body fat (Deurenberge, 1996). Though bioelectrical impedance enables estimates of fat and FFM, the assumptions, limitations, and errors that surround the theoretical basis and results, do not reflect positively on the method.

\section{Anthropometry}

Anthropometry is the science that deals with the measure of size and shape of the human body. Several types of anthropometric measurements exist and are regularly used by investigators including: segment lengths, breaths, widths, circumferences and skinfolds. Although there are many reasons warranting the collection of anthropometric data, the most popular is body fat assessment, despite the fact that this provides only an indirect measure (Ball, Altena, \& Swan, 2004). A valid concern of several researchers with regards to anthropometry is the potential for error or subjectivity of the measurements, such as correct anatomical landmarking (Fuller et al., 1991; Perini, de Oliveira, dos Santos Ornellas, \& de Oliveira, 2005). However, despite these limitations, many studies have reported accuracy, precision and reliability of such measurements, even between investigators (Jackson, Pollock, \& Gettman, 1978; Klipstein-Grobusch, Georg, \& Boeing, 1997). Anthropometry is an attractive method of body composition estimation, not only due to its accuracy, but because it is cost effective and easy to perform. 


\section{$\underline{\text { Skinfold Measurements }}$}

The measurement of skinfold thickness has been used as a practical means for body fat evaluation (Bray, Greenway, Molitch, Dahms, Atkinison, \& Hamilton, 1978). The theoretical basis of this method is that a majority of the body's fat store exists in the subcutaneous tissue, which is loosely attached to the underlying tissue. Therefore, a reasonable fat measurement can be made by pinching the skin and measuring the fold with a pair of callipers (Edwards, Hammond, Healy, Tanner, \& Whitehouse, 1955).

Limitations exist with this form of anthropometry. The first is the fact that not all body fat can be accounted for at the subcutaneous level. For example, it is known that fatty tissue exists, as a protective lining, around the body's internal organs. The second is that considerable variability can occur between studies based on methodological differences. How tightly the skin is pinched during measurement (Edwards, et al., 1955), and the anatomical location of the measurement (Bray et al., 1978), are important considerations. As a result of these types of limitations, greater error has been found for skinfolds than for other types of anthropometric measurements (Fuller et al., 1991). Error has also been observed to vary between individuals of differing body types, with error increasing with percent body fat (Nordhamn, Södergren, Olson, Karlström, Bessby, \& Berglund, 2000).

Despite these limitations, skinfold measurements have been considered an adequate method for the evaluation of a large number of people due to its easy execution, low cost, and relative accuracy (Perini et al., 2005). On their own, these are not good enough reasons to use this method for body composition estimation. However, skinfolds have been found to be accurate indicators of actual levels of fatness and fat distribution 
(Mueller \& Malina, 1987), and values obtained from skinfold calliper measurements are consistent with those of hydrostatic weighing (Womersley \& Durnin, 1977).

\section{Circumferences}

Segmental circumference measures may also be used to estimate percent body fat of the targeted segment. However, to use circumferences for total body estimates, a wide range of circumference locations may be utilized. It has been strongly recommended that, for body composition purposes, circumference measures be combined with regression equations. This recommendation stems from findings indicating that suppressor variables exist and may be useful for determining more accurate estimates of body fat percentages. For example, though arm and forearm circumferences do not correlate well with circumferences of the waist or gluteus, they can be used as predictors. This will allow waist and/or gluteus circumferences to be more valid estimates of percent fat (Pollock, Hickman, Kendrick, Jackson, Linnerud, \& Dawson, 1976). The reliability of this type of measurement is greater than that of skinfold thickness and is not affected by body type differences (Bray et al., 1978; Mueller \& Malina, 1987). Like skinfold thickness and other forms of anthropometry, circumference measurements are inexpensive to perform and easy to take.

\section{$\underline{\text { Summary }}$}

Increases in obesity have lead to an influx in research surrounding links of morbidity to increased percent body fat. Body composition is an important tool in the assessment of human mechanics and simulation. With the ever increasing knowledge of the human body it is now becoming possible to combine body composition data with 
biomechanical analysis via wobbling mass modeling to learn how body composition may affect in vivo mechanics. The body composition estimates derived by the outlined methods may be used as modeling inputs for better understanding the effects of musculoskeletal response and injury. It is important to bear in mind though, that traditional methods of body composition estimation, like hydrostatic weighing and bioelectrical impedance, are limited in their accuracy, availability, and suitability across a variety of demographics (Prior et al., 1997). With the assistance of modern imaging technologies, more complex and accurate measurement data may be acquired and used to validate some of the more traditional methods such as anthropometry. With the validation of these methods, researchers will not always be required to turn to expensive imaging techniques but will be able save both time and money, confidently using a traditional method.

\section{Imaging Technology}

Advances in technology, along with a demand of more complex body composition measurement, has lead to the development of imaging equipment. The most commonly used imaging techniques for this purpose include: computerized tomography (CT), magnetic resonance imaging (MRI), and dual energy x-ray absorptiometry (DXA).

\section{Computerized Tomography (CT)}

$\mathrm{CT}$ is an advanced imaging technique requiring rotating $\mathrm{x}$-ray tubes and $\mathrm{x}$-ray film. As the participant advances into the chamber, the tube rotates $360^{\circ}$. This produces a series of cross-sectional images at anatomically determined locations (Salamone et al., 2000) viewed from all around the subject. Through computer analysis, each $\mathrm{x}$-ray image 
from all angles can be reconstructed. As a result, the appearance of the images can be enhanced. CT shows a combination of soft and hard tissues while separating soft tissues into muscle tissue mass and adipose tissue mass (Salamone et al., 2000). CT may also be used to show fluid collection in the body (Yamaguchi, Yamauchi, Yamada, Ariyoshi, Ailawa, \& Kato, 2001). When used to aid in body composition evaluation, CT is not without its downfalls. As a result of the complexity of the CT machine, this technique is very costly. This is especially limiting for body composition research, which often involves relatively high participant recruitment. There are also some technical limitations that may compromise the application of the results obtained from CT. The fact that CT assesses adipose tissue rather than FM is its largest weakness for body composition estimation (Salamone et al, 2000). DXA however, may be a better choice than CT for body composition matters since it provides FFM and FM (Visser, et al., 1999). DXA also distinguishes the tissue types throughout the body, thereby limiting the amount of possible misclassification and allowing for more accurate results.

\section{Magnetic Resonance Imaging (MRI)}

The MRI machine is composed of a bed for the participant to lie down on and a tube into which the bed and participant slide. Magnets are built inside the $360^{\circ}$ of the tube's outer wall. These magnets, located across from one another, create a large magnetic field, which attracts positive forces, causing protons in tissues to align parallel to force fields. Following this alignment, radio waves are introduced at right angles, causing protons to "wobble" out of alignment. Termination of the radio waves causes realignment or relaxation, resulting in the return of protons to their original position. 
Changes in energy radiation are picked up by detectors in the tube when the protons return to their relaxed state.

MRI is therefore able to produce high resolution images that are clear enough to distinguish between healthy and diseased soft tissues. This ability to analyze the soft tissue of the living population is valuable, and as such, attempts have been made to use this tool to aid in body composition evaluation. Animal models and human cadaver studies have been used to verify the accuracy of the estimates of adipose tissue mass and its anatomical distribution in order to verify MR imaging of the living (Ellis, 2000). MRI has been shown to be well suited for assessment of whole body adipose tissue or lean tissue distribution using multi-slice models (Ross, 1996). MRI has been said to be better than $\mathrm{CT}$ for indicating the size and extent of most musculoskeletal soft-tissue masses (Sartoris \& Resnick, 1987). Though soft tissue analysis is a big part of body composition, analysis of the bone should not be disregarded. A downfall of MRI is that it does not distinguish bone, so the soft tissue surrounding the bone is blurred. Therefore, MRI is not a great selection for accurate bone mass estimates for body composition evaluation. In addition, the high cost of MRI is a significant drawback for its use, especially when there are other methods that are much less expensive (Sartoris \& Rensnick, 1987). This is less of an issue when evaluating a single patient, but becomes a more real concern when collecting data for a body composition study, which usually involves a large number of participants. It seems more viable to save MRI for clinical diagnosis of soft tissue abnormalities and use techniques that are better able to differentiate between tissues and include clear bone analysis for body composition estimation. 


\section{Dual Energy X-ray Absoroptiometry (DXA)}

DXA scanning is a more recent addition to the body composition measurement repertoire. This technology represents a significant advancement in techniques available for body composition research and evaluation (Ellis, 2000). DXA is the first method to include the assessment of bone mineral content (BMC) in its evaluation of the body's composition (Salamone, et al. 2000), and provides information about the general anatomical distribution of bone within the body (Ellis, 2000). Along with this, DXA has been considered a three-compartment model since it not only includes bone mineral mass, but also FM and FFM (Kohrt, 1998).

A DXA scanner works similarly to an X-ray, where the patient lays on a scanning table and either pencil or fan-beam photon $\mathrm{x}$-rays are passed through them to a detector. The information is then sent to the computer system, where the DXA software interprets and displays the data. DXA determines body composition based on measures of intensity of $\mathrm{x}$-rays, passed through the body, onto the detectors (Salamone, et al., 2000; Genton, Didier, Kyle, \& Pichard, 2002). The attenuation of the x-rays depends on the mass, density, and chemical composition of the tissue it has passed through. Since bone, lean tissue, and fat differ with respect to these aspects, the computer, using pixels, is able to make a map of the body and its components with their respective masses and locations within the body (Ellis, 2000; Genton et al., 2002).

DXA is an appealing method for body composition quantification because it goes a step further than other methods, by estimating bone mineral density along with soft tissue mass (Van Loan, 1998). These measurements are all gathered in one scan which only takes between 5 and 20 minutes to perform. Since results are available immediately (Ellis, 2000), the convenience, combined with timeliness of the procedure, adds to its 
attraction for researchers. DXA is also beneficial for participants since the only cooperation necessary involves lying motionless while the scan is completed (Bracco, Thiébaud, Chioléro, Landry, Burckhardt, \& Schutz, 1996). This non-invasive procedure also avoids the claustrophobic conditions of other methods such as CT and MRI (Haarbo, et al., 1991; Van Loan, 1998).

One of the greatest allures of DXA though is that it provides regional assessment of the body (Van Loan, 1998). Further, it provides both peripheral and central regional measurements of different soft tissue types (Mazess, Barden, Bisek, \& Hanson, 1990). This is valuable as it offers the potential for determining the importance of altered fat distribution in population studies of many important disease states (Ley, Lees, \& Stevenson, 1992).

Despite the many advantages of DXA, it is not without limitations. One of these limitations stems directly from the premise behind the method. DXA results are based on three variables calculated to represent bone, lean tissue and fat. Since the computer pixels are measured based on two parameters (attenuation at low and high energy), it is not mathematically possible to resolve the system (two equations with three unknown variables) without some assumptions being made (Bracco et al., 1996). DXA makes three main assumptions to attain the three variables. The first may imply that the composition of soft tissue overlying bone must have the same composition as the surrounding tissues. Another possible assumption with the use of DXA is that potential bone pixels with a small amount of calcium (below the threshold value) may be counted as lean tissue rather than bone. This misallocation would result in a minute misrepresentation of both bone and lean tissue for that pixel. And thirdly, the most commonly referred to assumption involves in vivo hydration of FFM. To avoid the interference of water content, DXA 
software assumes that the lean tissue contains about $73 \%$ water (Bracco et al., 1996). With this final assumption, measurement of FM is relatively unaffected by fluctuations in hydration status (Kohrt, 1998), so those measured with DXA do not need to have regulated water intake and physical activity prior to the scan. These assumptions made in the DXA process affect such a small percentage of the pixels that, though they allow for highly accurate calculations of the desired variables, their overall effects are miniscule.

Beam hardening is another concern when considering DXA. Beam hardening occurs because DXA is calibrated with phantoms, representing either the spine or hip, which may not be appropriate for other parts of the body, such as the forearm (Blake, McKeeney, Chhaya, Ryan, \& Fogelman, 1992; Wellens et al., 1994). Beam hardening preferentially removes lower energy photons from the radiation beam compared to the higher energy photons. This may cause a shift in the spectral distribution from low to higher effective energies with increasing body thickness. As a result, the attenuation coefficients for bone and soft tissue used in the DXA equation may depend on body thickness varying between participants, and even body parts (Blake et al., 1992). It has been shown though, that despite the possibility of beam hardening, this should be only a minimal concern regarding DXA's ability to predict body fat (Jebb, Goldberg, Jennings, \& Elia, 1995).

Radiation has also been a concern of participants when using DXA since this method uses ionizing radiation. However, the radiation dose from one whole body scan has been measured to be negligible, typically less than $1 \mathrm{mRem}$ (Ellis, 2000; Haarbo, et al., 1991). In fact, Fuller, Laskey, and Elia (1992) found that the resultant radiation dose to the skin was only measured to be about $0.075 \mathrm{mRem}$ per scan. This number is exceedingly small, especially considering that the effective dose of radiation required for 
multi-slice CT is estimated from 800 to $900 \mathrm{mRem}$ (Nieman, Cademartiri, Lemos, Raaijmakers, Pattynama, \& de Feyter, 2002; Kemerink et al., 2003). Considering that the average, annual dose of radiation in the United States is approximately $360 \mathrm{mRem}$ (United States Nuclear Regulatory Commission, 2005), the amount of radiation that participants are exposed to for one full body DXA scan is less then they would naturally be exposed to over the course of one day.

Depending on the type of research, it should be noted that some studies have reported that results from a DXA machine from one company should not be directly compared to that of another company, or if two scans are to be performed it is important that the same type of machine is used. This consideration has been suggested since DXA instruments produced by different manufacturers may provide slightly different results (Van Loan, 1998). There are several factors that may contribute to such differences, including: varying assumptions made on behalf of the DXA, different software versions, or differing components making up the DXA. For example, some scanners use a pencilbeam while others use a fan-beam. However, these differences should not significantly affect the results since research has shown that both types of scanning methods perform similarly (Visser et al., 1999). Pencil-beams are usually considered more accurate, but slower than fan-beam scanners. Recent research has shown though that little difference exists, not only between pencil- and fan-beams, but between manufacturers as well (Ioannidou et al., 2003).

Another limitation of DXA technology is the price. The cost of DXA compared to other imaging techniques is very good. However, this price is still very costly compared to other forms of body composition research such as anthropometry (Haarbo, et al., 1991). These types of methods though are not as accurate as DXA and some may also 
require further investigation by way of a reference method, whereas DXA is totally independent (Van Loan, 1998).

Despite its few limitations, DXA is gaining popularity as the best practical criterion measure in body composition assessment (Ball, Altena, \& Swan, 2004). DXA has been validated by several studies and found to be worthy of "prime time" within the realm of clinical evaluation of body composition (Van Loan, 1998). Several qualities have led to this positive feedback, at the forefront of which is the precision and accuracy of the measurements for in vivo study, coupled with the added ability to investigate specific regions or segments (Haarbo et al., 1991; Fuller et al., 1992). DXA is also popular due to its ability to directly assess fat distribution (Fuller et al., 1992), as opposed to other non-imaging techniques such as anthropometry and hydrostatic weighing, which are a step further removed. It is important, when using in vivo imaging, that the limitations are remembered, since there is no perfect method for body composition measurement. Taking this into consideration, along with the high costs of imaging technology, the ability to predict tissue masses from simple anthropometric measurements, generated through validated regression analysis, becomes increasingly advantageous.

\section{Prediction Equations for Body Composition Estimation}

The idea of using traditional body composition methods to develop prediction equations is not a new one. In fact, the first regression equations to predict body density with anthropometric variables, were developed over fifty years ago when the advantages of this approach were realized (Jackson \& Pollock, 1978). The most commonly used method for developing prediction equations is anthropometry, specifically skinfold 
thickness to determine percent body fat. Along with skinfolds, segment circumferences have also been used to predict body composition (Jackson \& Pollock, 1978). Several other traditional methods including bioelectrical impedance, total body water, potassium counting, and hydrostatic weighing (Wilmore $\&$ Behnke, 1970; Sun et al., 2003) have been used to predict body fat, lean body weight, and body density. Though there are some limitations, these methods have been largely accepted. One of the limitations is that prediction equations tend to be population specific for gender, age, and/or body type (Jackson \& Pollock, 1978; Lean, Han, \& Deurenberg, 1996). Another limitation is that, until recently, no study had developed prediction equations that would allow for the estimation of soft tissue masses and bone density in living people. This type of work has become possible with the advent of modern imaging technologies. The development of prediction equations for determining these masses in vivo would allow for more accurate biomechanical modeling of the body in highly dynamic or impact situations.

As alluded to earlier, few studies have chosen to include WM estimates in their predictive equations. Further, none of these studies have focused on the tissue masses of the upper extremities. Past work has been focussed on the lower extremities. Holmes and colleagues (2005) performed an in depth study of the lower extremities, taking 24 anthropometric measurements from each participant bilaterally. The measurements included segment lengths (6), circumferences (6), breadths (8), and skinfolds (4). DXA was used as a reference method for the development of prediction equations for fat mass, lean mass, wobbling mass and bone mineral content for the thigh, leg, and leg and foot segments. In general, the predicted tissue masses were found to be highly correlated with the DXA measures $\left(\mathrm{R}^{2}=0.85\right.$ to 0.96 , for LM and $\left.\mathrm{WM}\right)$. However as previously stated, 
this study only investigated the lower extremities. Similar work has yet to be completed for the upper extremities. 


\section{METHODS}

Participants

Participants consisted of young adults ranging in age from 17 to 30 years. They were primarily recruited from the Department of Kinesiology at University of Windsor. Recruitment occurred mainly in undergraduate classes, following a brief information session regarding the study, including the purpose, and an overview of the methods and incentives for their involvement. Incentives offered to the participants, for volunteering their time, included a free kinesiology research t-shirt and a printout of their personal full body DXA scan. Each printout included a scanned image of their body with details regarding the mass and composition of body segments. Both female and male participants were recruited, and data were collected from 100 people in total, in order to further improve statistical, predictive power observed by Holmes et al. (2005). All procedures were approved by the University of Windsor Research Ethics Board (see Figure A1, Appendix) as well as the ethics board of Windsor Regional Hospital. Participants were randomly assigned to two subgroups after the data collection was complete. The first group, comprised of $76 \%$ of the participants, was used for prediction equation generation for bone mineral content (BMC), fat mass (FM), lean mass (LM), and wobbling mass (WM) for each of the upper limb segments including the arm, forearm, and forearm and hand segments, independently. The second group ( $24 \%$ of the participants) was used as an independent group to validate the generated equations.

Volunteer participants were not to exceed $198 \mathrm{~cm}(6.50 \mathrm{ft})$ in height or $60 \mathrm{~cm}$ (1.97 ft) in width from shoulder to shoulder. These dimensions represent the maximum possible size of the DXA scan and are delineated by lines on the scanner bed that the 
participants lie on. Any mass situated outside of these lines would not be accounted for in the scan and would result in inaccurate segment mass measurements.

Instrumentation

\section{Anthropometry}

The purpose of this study was to predict in vivo segment tissue masses (BMC, FM, LM, and WM (WM = FM + LM $)$ ) from simple anthropometric measures. Segment lengths, circumferences, widths, and skinfolds (see Table 1 below) were taken with the use of a soft measuring tape (segment lengths and circumferences), small anthropometer (segment breadths) [Lafayette Instrument Company, model \# 01291], and skinfold callipers (skinfold thickness) [Slimguide Callipers, Creative Healthcare Products]. These measurement methods are cost effective, reliable, relatively easy to use, and widely accepted in research for the investigation of body composition (Georg, \& Boeing, 1997).

\section{$\underline{\mathrm{DXA}}$}

Actual tissue masses of the upper extremities were determined using DXA. These tissue masses included BMC, FM, LM, and WM for each segment of interest. DXA is accepted as a valid and reliable approach to body composition analysis and is commonly used for clinical and research applications (Haarbo et al., 1991; Fuller et al., 1992; Van Loan, 1998; Ball, Altena, \& Swan, 2004).

The DXA scanner used for this study was a GE Lunar Prodigy Advance, located at the Metropolitan campus of the Windsor Regional Hospital. This DXA scanner uses fan beam technology, resulting in high precision, and less than a $1 \%$ coefficient of variance for both BMD and total tissue values (GE Healthcare, 2004). The scan itself 
took approximately 5 minutes to complete, resulting in a radiation dose of about 0.04 $\mathrm{mRem}$ to the participant. This is less than the average radiation dose rate $(0.238 \mathrm{mRem})$ for one hour of a commercial airline flight (Feng, Chen, Sun, Duan, Jia, Zhang, 2002).

\section{Procedures}

Data collection for this study occurred in two parts. First, bilateral anthropometric measurements were taken for each participant. Participants were also scanned using the DXA machine to provide actual tissue masses for each body segment of interest. Each participant underwent both types of data collection on the same day, within minutes of each other.

A separate room at the hospital was available for the purpose of performing the anthropometric measurements. Two biomechanics graduate students, trained in anthropometric measurement, collected bilateral measures of both the upper and lower extremities in the form of 6 segment length measures, 6 circumference measures, 8 breadth measures, and 4 skinfolds for each extremity. Detailed descriptions of the anthropometric measurements taken are listed in Table 1 for the upper extremities and Table Al of the Appendix for the lower extremities (Note: the lower extremity data will be used in another study). The measurements listed in Table 1 parallel those successfully utilized by Holmes et al. (2005) for the lower extremities study (Table A1). All measurements were recorded to the nearest millimetre. One investigator obtained measurements from the right side while the other measured the left. All participants were instructed to wear shorts and t-shirts (or similar clothing) during measurement to enable reliable access to body landmarks. Participants were also requested to wear clothing that did not have any metal including buttons, zippers, snaps, or under-wires, that would 
interfere with the scan. It took approximately 15 minutes to measure each participant.

Therefore, the total time commitment for each participant was approximately 20 minutes.

Table 1: Description of upper extremity measurements taken bilaterally and recorded to the nearest millimetre, where (M-L) and (A-P) indicate that the measurements was taken in the medial-lateral and anterior-posterior directions, respectively.

\begin{tabular}{|c|c|}
\hline Variables & Measurement Descriptions \\
\hline Lateral Arm Length & $\begin{array}{l}\text { Distance between the acromion process and the } \\
\text { lateral aspect of the articular capsule of the elbow } \\
\text { joint }\end{array}$ \\
\hline Medial Arm Length & $\begin{array}{l}\text { Distance between the axilla and the medial aspect of } \\
\text { the articular capsule of the elbow joint }\end{array}$ \\
\hline Proximal Mid-Arm Length & $\begin{array}{l}\text { Distance between the axilla and the medial aspect of } \\
\text { the humerus at the level of maximum circumference } \\
\text { midway between the acromion process and the } \\
\text { articular capsule of the elbow joint }\end{array}$ \\
\hline Lateral Forearm Length & $\begin{array}{l}\text { Distance between the lateral aspect of the articular } \\
\text { capsule of the elbow joint and distal of the lateral } \\
\text { (radial) styloid process }\end{array}$ \\
\hline Medial Forearm Length & $\begin{array}{l}\text { Distance between the medial aspect of the articular } \\
\text { capsule of the elbow joint and the distal aspect of the } \\
\text { medial (ulnar) styloid process }\end{array}$ \\
\hline Proximal Mid-Forearm Length & $\begin{array}{l}\text { Distance between the medial aspect of the articular } \\
\text { capsule of the elbow joint and the medial aspect of } \\
\text { the ulna at the level of maximum forearm } \\
\text { circumference between the articular capsule of the } \\
\text { elbow joint and the styloids }\end{array}$ \\
\hline Arm Circumference & $\begin{array}{l}\text { Distance around the humerus and overlying tissue at } \\
\text { the level of the axilla }\end{array}$ \\
\hline Mid-Arm Circumference & $\begin{array}{l}\text { Maximum distance around the humerus and } \\
\text { overlying tissues midway between the acromion } \\
\text { process and the articular capsule of the elbow }\end{array}$ \\
\hline Elbow Circumference & Distance around the epicondyles of the humerus \\
\hline Mid-Forearm Circumference & $\begin{array}{l}\text { Maximal distance around the forearm midway } \\
\text { between the articular capsule of the elbow joint and } \\
\text { the styloids }\end{array}$ \\
\hline Wrist Circumference & $\begin{array}{l}\text { Distance around the ulna and radius, and overlying } \\
\text { tissues just proximal to the styloids }\end{array}$ \\
\hline Styloid Circumference & Distance around the styloids and overlying tissues \\
\hline Arm Breadth & $\begin{array}{l}\text { Distance across the humerus and overlying tissues } \\
\text { between the axilla and arm }\end{array}$ \\
\hline Mid-Arm Breadth (M-L) & $\begin{array}{l}\text { Distance across the humerus and overlying tissue at } \\
\text { the level of maximum circumference midway } \\
\text { between the acromion process and the articular }\end{array}$ \\
\hline
\end{tabular}




\begin{tabular}{|l|l|}
\hline & capsule of the elbow joint \\
\hline Mid-Arm Breadth (A-P) & $\begin{array}{l}\text { Distance across the humerus and overlying tissue at } \\
\text { the level of maximum circumference midway } \\
\text { between the acromion process and articular capsule } \\
\text { of the elbow joint }\end{array}$ \\
\hline Elbow Breadth (M-L) & $\begin{array}{l}\text { Distance across the widest aspect of the elbow joint } \\
\text { capsule. }\end{array}$ \\
\hline Mid-Forearm Breadth (M-L) & $\begin{array}{l}\text { Distance across the ulna and radius and overlying } \\
\text { tissues at the level of maximum forearm } \\
\text { circumference }\end{array}$ \\
\hline Mid-Forearm Breadth (A-P) & $\begin{array}{l}\text { Distance across the ulna and radius and overlying } \\
\text { tissues at the level of maximum forearrn } \\
\text { circumference }\end{array}$ \\
\hline Wrist breadth & $\begin{array}{l}\text { Distance between the lateral aspects of the ulna and } \\
\text { radius and overlying tissues just proximal to the } \\
\text { styloids }\end{array}$ \\
\hline Styloid Breadth & $\begin{array}{l}\text { Distance between the radial and ulnar styloid } \\
\text { processes and overlying tissues }\end{array}$ \\
\hline Medial Forearm (ulnar) Skinfold & $\begin{array}{l}\text { Vertical fold on the medial aspect of the forearm at } \\
\text { the level of maximum circumference }\end{array}$ \\
\hline Posterior Forearm Skinfold & $\begin{array}{l}\text { Vertical fold on the posterior aspect of the forearm at } \\
\text { the level of maximum circumference }\end{array}$ \\
\hline Anterior Arm (Bicep) Skinfold & $\begin{array}{l}\text { Vertical fold on the anterior aspect of the arm at the } \\
\text { level of maximum circumference midway between } \\
\text { the acromion process and the articular capsule of the } \\
\text { elbow joint }\end{array}$ \\
\hline Posterior Arm (Tricep) Skinfold & $\begin{array}{l}\text { Vertical fold on the posterior aspect of the arm at the } \\
\text { level of maximum circumference midway between } \\
\text { the acromion process and the olecranon process }\end{array}$ \\
\hline
\end{tabular}

Data were collected at the hospital over the course of three weekday evenings from 4:30 pm to $8: 00 \mathrm{pm}$ and two consecutive Saturdays from about 8:30 am to $4: 30 \mathrm{pm}$. These times were suggested by the hospital in order to avoid conflicts with their clinical patients. Each participant in this study was directed to the rooms used for anthropometry measurement and DXA scanning but participants were considered visitors of the clinic and were not admitted to the hospital.

Prior to scanning a participant, their mass and height were taken and each female was screened for pregnancy since even slight amounts of radiation can be harmful to a 
fetus in the early stages. For scanning, participants were asked to lie supine on the scanning bed with their arms at their side, palms facing down and their feet were bound together to ensure that all limbs remained inside the scan window parameters and that the body was aligned. Perimeter boundary lines were marked on the scan bed. It was important that all body parts remained inside these lines during the scan because any part of the body outside of the scan window would not be included in the scan, and would result in inaccurate body composition results. Participants were instructed to remove their jewellery and were asked to, in a private changing room provided, don a traditional hospital gown for their DXA scan, only if the clothing they were wearing had metal in it. An investigator was in the room with the hospital's DXA technicians during each scan to ensure the consistency of data collection.

Following the DXA scan, each participant was given a print-out containing a general overview of their personal whole body scan results. Data from each scan were saved in a computer file to be analyzed in the Ergonomics lab at the University of Windsor during the following weeks. Copies of each scan were also archived at the hospital in a separate database from that of their patients. These data will not be used by the hospital clinic, but were kept for their records of machine use.

\section{DXA Analysis}

Scan files were analyzed by the primary investigator using the DXA analysis software (enCORE, 2006, GE Healthcare, version 10.51.006). Data were also analyzed by a secondary investigator to assess the reliability of the segmentation methods (to be reported in a follow-up study). 
Although whole body scans were performed, this study focused on analyzing the data from the upper extremities only. The enCORE software allowed specific isolation of particular regions of interest (ROI) by creating a polygon around the desired area. This enabled the segmentation of the upper limbs from the rest of the body at the shoulder, and also allowed various analyses of the arm via segmentation at the elbow and wrist (see Figure 1). In doing so, the BMC, FM, LM, and WM of the right and left arm, forearm, and forearm and hand segments were determined.

The polygons used to outline the desired ROIs were comprised of straight adjoining lines. Therefore, the segmentation technique used was a combination of that of Dempster (1955) (see dashed lines in Figure 2) and Clarys and Merfell-Jones (1986) (see solid black lines in Figure 2). The straight lines of the polygon do not allow investigators to segment perfectly around bony processes, such as the humeral head of the shoulder (as per Clarys and Marfell-Jones, 1986), nor does the software have the capability to include all the muscle mass of the segment similar to Grand (1977) if it is outside the specified ROI. However, like Dempster and Clarys and Marfell-Jones, the joint space was targeted for each segmentation as accurately as possible to eliminate as much bone and soft tissue misallocation as possible from adjoining segments. 


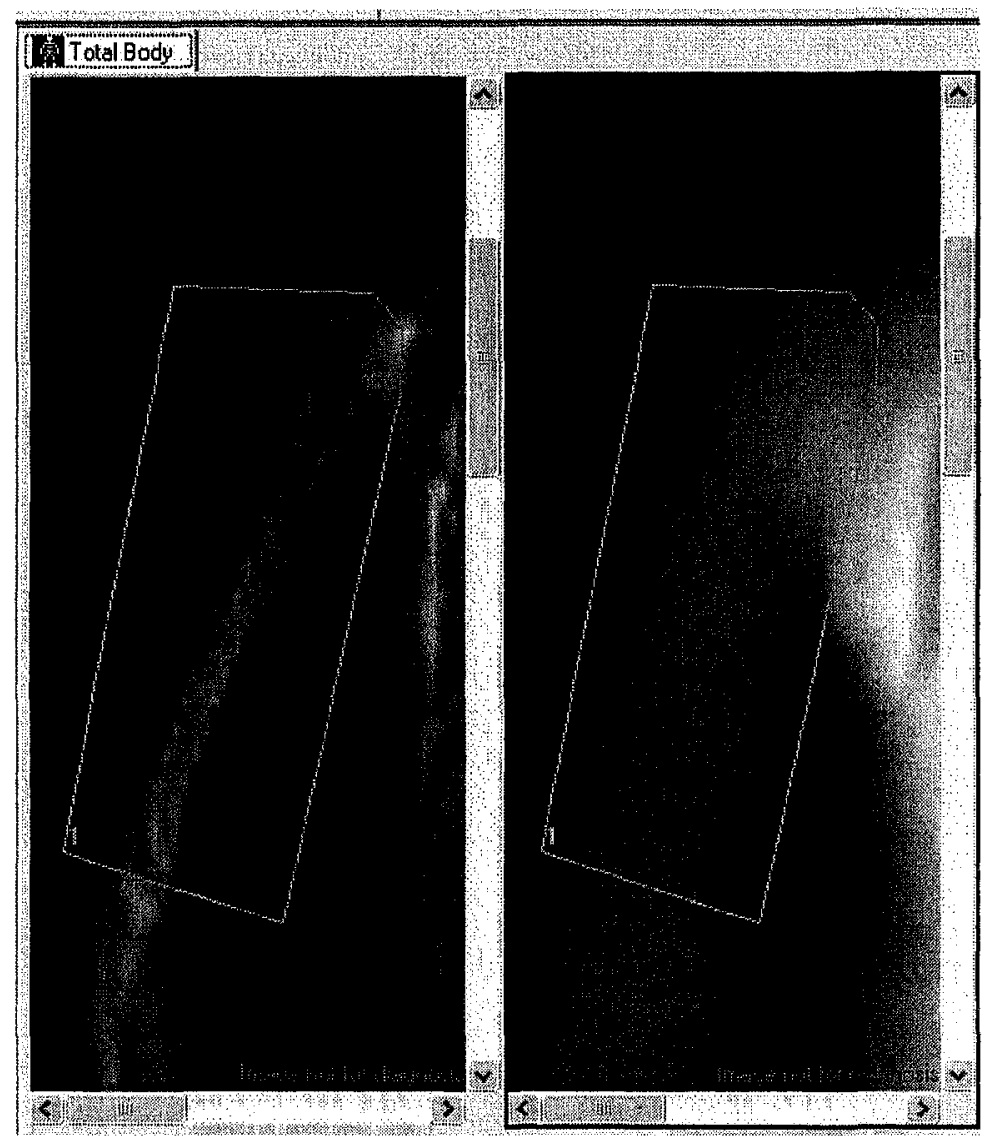

Figure 1: Region of interest selected from enCORE software including the arm, segmenting around the humeral head and at the elbow

A

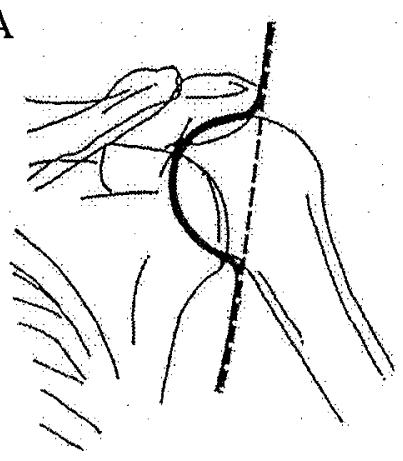

B

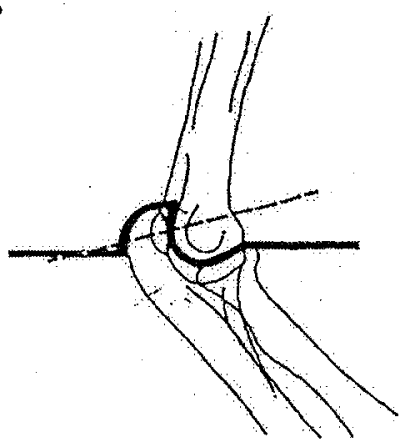

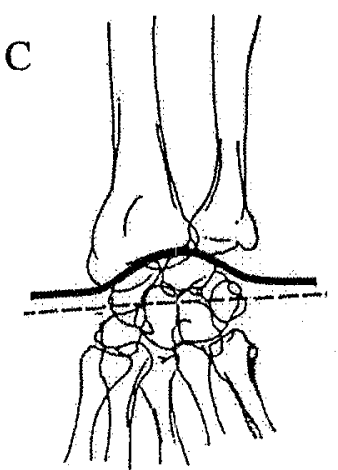

Figure 2: A. segmentation at the shoulder joint, B. segmentation at the elbow joint, and C. segmentation at the wrist. The dashed lines represent Dempster's segmenting technique (1955) and the solid black line represents the technique by Clarys et al. (1984) (figures are from Clarys \& Marfell-Jones, 1986). 
Statistical Analyses

All statistical analyses were performed using SPSS for Windows, version 15.0. $\underline{\text { Initial Analyses }}$

The measured anthropometric data and the tissue mass data from DXA for each participant were manually keyed into a computer for statistical analysis. The anthropometric data were comprised of sex, height, mass, and age, along with the 24 anthropometric measurements for each of the left and right sides of the body. The tissue mass data comprised BMC, FM, LM, and WM for each of the four segments on both the left and right sides of the body. Two segmentation trials with the DXA software were performed for each segment. Therefore, a total of 114 values were input for each of the participants.

To ensure the accuracy of the inputs, the differences and averages for each of the variables were calculated between the left and right sides. Sizable differences were then double checked with the original values. In addition, frequencies and scatter plots for each of the variables were analyzed to locate miss-typed values and to indicate possible univariate outliers. Values found outside the normally distributed range were verified against the original values. Any miss-keyed data were replaced with the actual value, while outliers were replaced by the mean value for that variable (Tabachnick \& Fidell, 2001).

In order to determine if there was a difference between the two methods of arm segmentation (i.e. the "whole shoulder method" where the region of interest extended superiorly from the axilla to include the whole shoulder verses the "humeral head method" where the region of interest encapsulated the humeral head only), a paired t-test 
was conducted. This was performed for each of the left and right sides and for each of the four tissue types; 8 pairs all together.

A one-way analysis of variance (ANOVA) was run to determine if there were significant differences between the first and second segmentation trials for each segment and each tissue type. This was done to determine the repeatability of the segmentation method used.

Sex differences were investigated between DXA tissue mass variables with a oneway ANOVA. If significant differences are found as a result of this analysis, sex may need to be coded for independently in the developed regression equations (see Section 3.5.2 below).

Differences in the DXA tissue masses and the anthropometric measures between the left and right sides of the body were analyzed using paired t-tests.

The total sample of 100 participants was divided into two subgroups. The generation group was composed of 76 randomly assigned participants ( 38 males and 38 females). The remaining 24 participants comprised the validation group. This independent group was used to assess the accuracy of the generated prediction equations (Jackson \& Pollock, 1978; Wang, et al., 2003; Holmes, et al., 2005). The between group participant ratio is similar to that used by Holmes and colleagues (2005).

Levene's test for homogeneity of variance was conducted on the generation and validation group variables to ensure that between group discrepancies across the variables were minimized. The equality of variance between groups is important for an accurate validation of the generated equations.

Means and standard deviations between the sample groups and sexes were analyzed to ensure between group similarities for each of the variables. A one-way 
ANOVA was performed to determine if there were any sex differences for all anthropometric measures within the generation sample.

A correlation matrix was generated for the anthropometric variables to determine if any pair was highly correlated. Highly correlated variables may lend themselves to possible elimination in the regression analysis, or cause problems resulting from inflation or deflation if the variance explained due to redundance that highly correlated variables may cause. This step also helped to simplify the resulting prediction equations and enhanced the variable to participant ratio for the generation sample, before variables are stepped in or out of the regression analysis. This procedure helped ensure that the most relevant and true predictive measures were included in the final regression models.

\section{Prediction Equation Generation}

The prediction equations were generated by way of multiple linear stepwise regression. This method uses a combination of forward selection and backward elimination, and was used to determine the best predictors and final equations for BMC, FM, LM, and WM of the arm, forearm, and forearm with hand segments separately. Predictor variables included segment lengths, circumferences, breadths, skinfold measures, sex, height, and mass. When using multiple linear regression analysis, certain statistical assumptions are made. These assumptions include: the absence of outliers, normality and homoscedasticity, and the absence of multicollinearity.

\section{$\underline{\text { Outliers }}$}

Outliers are data cases that fall outside the normal range of the rest of the data. These cases must be treated before regression analysis because they may largely impact 
equation generation and could greatly increase the standard error of the regression model (Tabachnick \& Fidell, 2001). Both univariate and multivariate outliers were screened for. As previously stated, univariate outlier screening included the use of descriptive statistics, frequencies and scatter plots. In addition, histograms were analyzed to determine normal bell-shaped, grouped scores. Z-scores were also calculated, with values exceeding \pm 3.29 considered as outliers.

Multivariate outliers were screened using Mahalanobis distance at the time of regression analysis in order to avoid screening based on desired outcome, and over-fitting data by making unnecessary deletions along with the outliers (Tabachnick \& Fidell, 2001). SPSS calculates a minimum, maximum and mean value for Mahalanobis distance. The maximum value was selected to ensure a conservative analysis. This value was then compared to a chi-square critical value, using a $P$ of 0.001 and degrees of freedom minus one $(d f-1)$, whereby the $d f$ is equal to the number of independent variables (IVs) - 1 . If a case had a Mahalanobis maximum value that was greater than the chi-square critical value, then a multivariate outlier was assumed. If this analysis indicated an outlier, Cook's distance was used to indicate whether the outlier played a significant role in the regression analysis. If Cook's distance was not significant (i.e. $<1.0$ ), the involved variable was not omitted because it did not represent an influential data point.

\section{Normality and Homoscedasticity}

Normality is the assumption that the variables are normally distributed. This was initially assessed with the use of histograms, normal probability plots (P-P plots), and by evaluating the skewness and kurtosis statistics, where normality is increasingly violated the further skew or kurtosis deviates from zero. A common method for detecting non- 
normality is to determine the ratio between the skewness and kurtosis statistic and their respective standard errors (statistic/standard error). For an alpha level of 0.05 , it is suggested that this ratio should not greatly exceed \pm 1.96 (Stevens, 2002). However, Tabachnick and Fidell (2001) suggest that, for samples of around 100 or more cases, the significance of the level of skewness is less important than the actual size. As a result, it is useful to use Kline's (1998) rule of thumb: accepting an absolute skew value of $<3$, and kurtosis value of $<10$. Both of these analyses were assessed in this study to investigate normality.

Another method used to evaluate normality was to plot the residuals after the regression analyses were performed. This analysis was also used to evaluate linearity and homoscedasticity. Normality was identified if the residuals plotted were evenly distributed across the " 0 residuals (errors)" line. Linearity was identified with residuals in a line along the "0 residuals (errors)" line. An example of non-linearity would be a plot representing a curve with a "U" shape. Linearity was also observed using the normality plots initiated to assess the prior assumption. Homoscedasticity was a safe assumption if the values were evenly distributed away from the " 0 residuals (errors)" line, within the range of the trend for that variable (not a specified cut-off distance).

\section{Multicollinearity}

Multiple linear regression also assumes that there is an absence of multicollinearity among the IVs of the regression. Multicollinearity occurs when the IVs are very highly correlated, and may result in an unstable matrix. The redundant variables inflate the size of the error and weaken the analysis (Tebachnick \& Fidell, 2001). In cases such as this, these variables were considered redundant and only one was selected 
to continue into the regression analysis. Multicollinearity was assessed with the collinearity diagnostics, calculated along with the regression. An indication of multicollinearity exists when the tolerance value is $<0.1$ (Norusis, 2005), or when the variance inflation factor (VIF) is $>10$ (Kline, 1998). The tolerance value is a measure of the strength of the linear relationships of the IVs. It is the proportion of the variability of that variable that is not explained by its relationships with other IVs in the model. The VIF value is the reciprocal of the tolerance value, measuring the increase in variance of the coefficients due to the correlations of the IVs (Norusis, 2005).

The initial evaluation of the prediction equations for each of the tissue masses for each segment was to assess the adjusted squared multiple correlation $\left(R^{2}\right)$ and the standard error of the estimate (SEE). The $R^{2}$ value is a representation of the amount of explained variance of the DV by the IVs, where 1.0 is the perfect score (all the variance is explained). There is no cut-off value for $R^{2}$ that indicates an acceptable amount of predictive power for the equation, however, predictive power increases as $R^{2}$ approaches 1.0. The SEE value is reported in the standard unit of measurement of the analysis; in this case, it represents the standard error in grams of the predicted output.

\section{Prediction Equation Validation}

In order to assess the accuracy of the produced regression equations, anthropometric data from the validation group (12 males and 12 females) were entered into the equations. The predicted tissue masses from each were then compared to the actual masses measured by DXA for each participant. The difference between the predicted and actual masses was calculated, along with the percent error and the root mean squared error $\left(\mathrm{RMS}_{\mathrm{error}}\right)$. 
Scatter plots of the predicted and actual masses were created and simple linear regression was performed to quantify the relationship between the predicted and actual tissue masses. The resultant simple regression equations were reported, together with the amount of variance explained (i.e. $R^{2}$ values). 


\section{IV.RESULTS}

Initial Results

Accuracy of Data Input

Significant differences between entered anthropometric data for left and right sides, and between trial one and trial two for the DXA measured tissue masses, were cross-checked with the original data set and, in most cases, were found to be miss-keyed. The miss-keyed data were then corrected. Frequencies and scatter plots confirmed that these data had been correctly entered. Only one case remained for which the deviation from the rest of the data could not be explained. This outlier was the left elbow circumference of a participant, which was $14.7 \mathrm{~cm}$ in magnitude. This was $11 \mathrm{~cm}$ below the mean value for this variable, thus it was replaced with the group mean value.

\section{Variable Analysis}

The arm segment masses determined from the two segmentation methods at the shoulder joint, were found to be very highly correlated $(r>0.991)$, but statistically significant $(P<0.05)$. There were no significant differences between the masses from the first and second segmentation trials $(P<0.05)$. Therefore, values from the two trials easily lent themselves to combination and were averaged together. Significant differences $(P<0.05)$ were found to exist between the sexes in all but three of the tissue masses: left and right thumb BMC ( $P=0.223$ and 0.535 , respectively), and whole shoulder arm FM $(P=0.075)$. Mean scores for the left and right sides were found to be statistically different for all DXA variables $(P<0.05)$ and for 13 of the 24 anthropometric measurements. The right side was found to be greater for $75 \%$ of the measurements, but the mean difference between sides was only $5 \%$ and did not exceed $21 \%$. Despite these 
differences, left and right side measurements were averaged since separate regression equations for left and right sides of the body were not deemed useful or practical.

\section{Between Sample Group Analyses}

Homogeneity of variance between the IVs of the generation sample group $(N=$ 76) and the validation sample group $(\mathrm{N}=24)$ were performed using Levene's statistic via ANOVA. All of the anthropometric variables were found to be homogeneous between the generation and validation groups $(P>0.05)$.

Means and standard deviations were calculated independently of sex for each of the IVs, age and BMI. This was done with each of the sample groups separately (Table 2). No significant differences were found between the generation and validation samples. Significant sex differences $(P<0.05)$ were found within the generation sample for only lateral arm length and proximal arm breadth.

\section{Independent Variable Assessment}

Correlations between independent variables (IVs) ranged from $R=0.343$ to 0.957 , with many of the variables correlating highly to each other $(R>0.80)$. Highly correlated variables were targeted for elimination prior to the stepwise regression procedure. Based on the correlations analysis, reliability of the measurement (Burkhart, Arthurs, \& Andrews, 2007), measurement type, and direction of measurement, the number of IVs was reduced from 16 to 11 for the arm, and from 17 to 11 for the forearm and forearm and hand segments (these segments included the same variables). Height, mass, sex, and elbow circumference were common variables for all three segments. 
Table 2: Mean $( \pm S D)$ scores of the general physical characteristics and anthropometric measures for male and female participants in both sample groups.

\begin{tabular}{|c|c|c|c|c|c|c|c|c|}
\hline \multirow{3}{*}{$\begin{array}{l}\text { Variable/Measure } \\
\text { Physical Characteristics }\end{array}$} & \multicolumn{4}{|c|}{ Generation Sample $(n=76)$} & \multicolumn{4}{|c|}{ Validation Sample $(n=24)$} \\
\hline & \multicolumn{2}{|c|}{$M(n=38)$} & \multicolumn{2}{|c|}{$F(n=38)$} & \multicolumn{2}{|c|}{$M(n=12)$} & \multicolumn{2}{|c|}{$F(n=12)$} \\
\hline & & & & & & & & \\
\hline Age (yrs) & 21.8 & (2.7) & 21.8 & (1.7) & 22.0 & $(2.7)$ & 21.3 & $(1.1)$ \\
\hline Height $(m)$ & 1.8 & $(0.1)$ & 1.7 & $(0.1)$ & 1.7 & $(0.0)$ & 1.7 & $(0.1)$ \\
\hline Mass $(\mathrm{kg})$ & 78.9 & $(11.8)$ & 62.0 & (9.2) & 75.6 & (10.1) & 64.5 & $(10.8)$ \\
\hline BMI $\left(\mathrm{kg} / \mathrm{m}^{2}\right)$ & 25.4 & $(3.1)$ & 22.6 & (3.5) & 25.1 & $(3.6)$ & 22.8 & $(2.9)$ \\
\hline \multicolumn{9}{|l|}{ Lengths (cm) } \\
\hline $\operatorname{Arm}(L)$ & 31.0 & $*(1.7)$ & 29.2 & (1.5) & 30.3 & (1.7) & 30.5 & $(2.0)$ \\
\hline $\operatorname{Arm}(\mathrm{M})$ & 25.9 & $(1.3)$ & 24.7 & (1.3) & 25.8 & (1.3) & 25.7 & $(2.2)$ \\
\hline Arm (prox, mid) & 13.5 & $(1.0)$ & 12.6 & $(1.2)$ & 13.2 & $(0.9)$ & 12.6 & $(1.6)$ \\
\hline Forearm (L) & 27.5 & (1.4) & 25.9 & $(1.0)$ & 27.1 & $(0.6)$ & 26.4 & (1.5) \\
\hline $\begin{array}{l}\text { Forearm (M) } \\
\text { Forearm (prox }\end{array}$ & 25.5 & (1.3) & 24.1 & (1.0) & 25.2 & (1.3) & 24.5 & (1.4) \\
\hline mid) & 11.7 & $(0.9)$ & 11.6 & $(0.8)$ & 11.9 & $(0.8)$ & 11.9 & (1.1) \\
\hline \multicolumn{9}{|l|}{ Circumferences $(\mathrm{cm})$} \\
\hline Arm (prox) & 34.1 & (3.1) & 28.9 & $(2.8)$ & 33.8 & (3.2) & 30.4 & $(3.0)$ \\
\hline Arm (mid) & 31.7 & (3.1) & 26.8 & (2.5) & 31.1 & (3.0) & 27.3 & $(2.8)$ \\
\hline Elbow & 27.8 & $(2.2)$ & 23.7 & $(1.9)$ & 27.5 & $(2.4)$ & 24.0 & (1.8) \\
\hline Forearm (mid) & 26.1 & (2.4) & 22.0 & (1.7) & 25.5 & $(2.1)$ & 21.8 & (1.8) \\
\hline Wrist & 17.8 & $(1.2)$ & 15.5 & $(0.9)$ & 17.7 & $(1.0)$ & 15.6 & $(1.0)$ \\
\hline Styloid & 17.5 & $(1.0)$ & 15.3 & $(0.7)$ & 17.4 & $(0.9)$ & 15.3 & $(0.8)$ \\
\hline \multicolumn{9}{|l|}{ Breadths (cm) } \\
\hline Arm (prox) & 11.1 & $*(1.1)$ & 9.8 & $(1.0)$ & 10.6 & $(1.0)$ & 10.3 & (1.1) \\
\hline $\operatorname{Arm}(\mathrm{mid}, \mathrm{M} / \mathrm{L})$ & 8.5 & $(0.8)$ & 7.3 & $(0.8)$ & 8.5 & $(0.9)$ & 7.7 & $(0.8)$ \\
\hline Arm (mid, A/P) & 10.1 & $(1.2)$ & 8.1 & $(0.9)$ & 9.8 & $(1.0)$ & 8.2 & $(1.0)$ \\
\hline Elbow & 9.0 & $(0.6)$ & 7.8 & (0.6) & 8.8 & $(0.7)$ & 7.9 & $(0.8)$ \\
\hline Forearm (mid, $M / L)$ & 8.3 & $(0.7)$ & 6.9 & $(0.6)$ & 8.1 & $(0.7)$ & 6.9 & $(0.5)$ \\
\hline Forearm (mid, A/P) & 6.7 & $(0.6)$ & 5.7 & $(0.5)$ & 6.7 & $(0.6)$ & 6.8 & $(0.5)$ \\
\hline Wrist & 5.9 & $(0.4)$ & 5.2 & $(0.3)$ & 5.8 & $(0.4)$ & 5.3 & $(0.4)$ \\
\hline Styloid & 5.8 & $(0.4)$ & 5.1 & $(0.3)$ & 5.7 & (0.3) & 5.2 & $(0.3)$ \\
\hline \multicolumn{9}{|l|}{ Skinfolds $(\mathrm{mm})$} \\
\hline Forearm (mid, M) & 4.3 & (1.2) & 6.3 & $(2.5)$ & 4.5 & $(1.0)$ & 7.4 & $(2.2)$ \\
\hline Forearm (mid, P) & 4.3 & $(1.2)$ & 5.9 & (2.7) & 4.3 & $(0.8)$ & 6.6 & (1.4) \\
\hline $\operatorname{Arm}(\mathrm{mid}, \mathrm{A})$ & 5.1 & $(2.4)$ & 7.0 & $(2.0)$ & 4.5 & $(0.9)$ & 7.8 & $(2.5)$ \\
\hline Arm (mid, P) & 11.4 & $(4.3)$ & 15.9 & (5.6) & 10.5 & (3.7) & 18.0 & $(5.0)$ \\
\hline
\end{tabular}

Note: $\mathrm{A}=$ anterior $; \mathrm{P}=$ posterior; $\mathrm{M}=$ medial; $\mathrm{L}=$ lateral; mid = midpoint of the segment between anterior and posterior or medial and lateral surfaces.

*Sex difference within generation sample significant at $P<0.05$. 
Prediction Equation Generation

Testing Assumptions

Outliers

Univariate outliers were initially screened for using frequencies and scatter plots. Histograms were also used to visually evaluate the data range and distribution for each variable. No abnormalities or extreme data were detected with this analysis. Z-scores were less than the predetermined cut-off value of \pm 3.29 for all variables, except posterior arm skinfold $(z=3.30)$. It was decided to leave this case in since the extremeness of the standardized score depends on the size of the sample. With a large sample size, a few zscores greater than 3.29 are expected (Tabachnick \& Fidell, 2001) and the difference between the cut-off value and the score was minimal $(0.01)$.

Eight of the 12 equations indicated the presence of multivariate outliers where the Mahalanobis maximum value exceeded the cut off value indicated by the chi-square analysis. The remaining four equations, LM for the arm, and WM for all three segments, did not indicate the presence of multivariate outliers. Cook's distance was applied to assess whether the equations that had Mahalanobis distances suggesting the presence of multivariate outliers, would significantly change the regression coefficient if the offending case were to be deleted (Tabachnick \& Fidell, 2001). In each case, Cook's distance indicated insignificant effects (Cook's distance $\leq$ 0.484). Therefore, deletion of cases was not necessary.

Normality and Homoscedasticity

The normal probability plots (P-P plots) showed data clustered along the "expected cumulative probability" (y-axis) verses "observed cumulative probability" (x- 
axis) line. This was the case for all tissue mass segments following regression analysis. The skew ratio was violated in the four skinfold measurements and the kurtosis ratio was exceeded in the arm circumference, styloid circumference, mid-forearm breadth (M-L), posterior forearm skinfold, medial forearm skinfold, and anterior arm skinfold measurements. Based on Kline's rule of thumb, there were no violations of normality in either skew or kurtosis as values did not exceed 2.4 or 4.9 , respectively.

Residual plots showed that data were normally distributed, with the exception of a few cases of minor clustering. This analysis, in conjunction with the others described above, resulted in the conclusion that the assumption of normality was satisfied.

Linearity was indicated by the residual plots as the data were located around/along the residual errors line at zero. In addition, the assumption of homoscedasticity was satisfied as the residual data were found to be evenly distributed along the zero errors line.

\section{Multicollinearity}

Multicollinearity was assessed at the time of regression analysis with the collinearity diagnostics provided. After the first set of equations was developed, it was discovered that four of the 12 equations had multicollinearity problems. The affected equations included LM of the arm as well as the WM for all three segments. The offending variables were arm circumference and mid-arm breadth (A-P) for LM and WM of the arm segment, styloid and elbow circumference for WM of the forearm, and styloid circumference for the WM of the forearm and hand segment. The offending variables were removed from the analysis and new equations were developed. The new equations 
did not have multicollinearity problems. However, they did result in slightly lower adjusted $\mathrm{R}^{2}$ values and higher $\mathrm{SEE}$ values than the initial equations.

\section{Prediction Equation Evaluation}

Following data cleaning procedures, 12 prediction equations were generated, each from 11 IVs, and their respective adjusted $R^{2}$ and SEE values were noted (see Table 3 ). All adjusted $R^{2}$ values were $\geq 0.85$, where LM and WM of the forearm resulted in an $R^{2}$ value of 0.968 . $F$ values ranged from 89.07 (BMC forearm + hand) to 457.78 (WM forearm) and were significant at alpha $<0.05$. SEE values ranged from $7.74 \mathrm{~g}$ (BMC forearm) to $154 \mathrm{~g}$ (LM arm).

Prediction Equation Validation

Anthropometric data from the validation sample group were entered into the generated equations to validate their predictive ability. Mean errors were $< \pm 31$ grams, with the largest errors occurring in the LM of the arm and the forearm and hand (Table 4). The smallest mean error was noted for the WM of the arm $(0.25 \mathrm{~g})$. Mean percent errors ranged from $15.5 \%$ to $-2.2 \%$, where 10 of the 12 equations resulted in mean errors of $< \pm$ 4.3\%. $\mathrm{RMS}_{\text {errors }}$ ranged from $7.9 \mathrm{~g}$ to $180.3 \mathrm{~g}$, with 9 of 12 equations having $\mathrm{RMS}_{\text {errors }}$ of $<86.0 \mathrm{~g}$.

The actual and predicted tissue masses were highly correlated, as seen in the scatter plots in Figure 3, with $R^{2}$ values ranging from 0.68 (LM of the forearm) to 0.97 (WM of the arm). Generally, WM tissues generated the highest $R^{2}$ values compared to the other tissue masses. 
Table 3: Prediction equations for BMC, FM, LM, and WM tissues of the arm, forearm, and forearm + hand segments.

\begin{tabular}{|c|c|c|c|}
\hline Mass type and Location & $\begin{array}{c}\text { Eq } \\
\#\end{array}$ & $\begin{array}{c}\text { Adj. } \\
\mathbf{R}^{2}\end{array}$ & $\begin{array}{c}\text { SEE } \\
(\mathrm{g})\end{array}$ \\
\hline $\begin{array}{l}\text { Bone Mineral Content Mass (BMC) } \\
\mathbf{Y}^{1}(\operatorname{arm})=-310.134+5.52(\mathrm{x} 1)+102.064(\mathrm{x} 2)+3.386(\mathrm{x} 3)\end{array}$ & 1 & 0.866 & 9.4 \\
\hline $\begin{array}{l}\mathbf{Y}^{1}(\mathbf{f o r e a r m})=-196.308+4.343(\mathrm{x} 4)+37.94(\mathrm{x} 2)+3.037(\mathrm{x} 1)+ \\
2.333(\mathrm{x} 5)-1.14(\mathrm{x} 6)\end{array}$ & 2 & 0.862 & 7.7 \\
\hline $\begin{array}{l}Y^{1}(\text { forearm+hand })=-269.554+6.743(x 4)+54.823(x 2)+3.675(x 1)+ \\
3.172(x 7)-1.508(x 6)\end{array}$ & 3 & 0.854 & 10.7 \\
\hline
\end{tabular}

\section{Fat Mass (FM)}

$\mathbf{Y}^{1}(\mathbf{a r m})=-653.914+18.560(\mathrm{x} 8)+7.72(\mathrm{x} 9)+21.098(\mathrm{x} 10)-$

$94.972(\mathrm{x} 11)+30.172(\mathrm{x} 12)$

$\begin{array}{lll}4 & 0.870 & 79.7\end{array}$

$\mathbf{Y}^{1}($ forearm $)=148.929+10.539(x 6)+1.996(x 9)+11.023(x 13)-$ $180.851(\mathrm{x} 2)$

$\begin{array}{lll}5 & 0.861 & 22.5\end{array}$

$\mathbf{Y}^{1}($ forearm+hand $)=135.618+10.297(\mathrm{x} 6)+2.163(\mathrm{x} 9)+10.867(\mathrm{x} 13)$

$-173.159(\mathrm{x} 2)$

$\begin{array}{lll}6 & 0.860 & 22.4\end{array}$

\section{Lean Mass (LM)}

$\mathbf{Y}^{\mathbf{1}}(\mathbf{a r m})=-3621.559+85.810(\mathrm{x} 1)-37.805(\mathrm{x} 8)+75.424(\mathrm{x} 14)+$

$55.056(\mathrm{x} 3)-27.816(\mathrm{x} 10)$

$\begin{array}{lll}7 & 0.942 & 154.8\end{array}$

$\mathbf{Y}^{1}($ forearm $)=-2193.008+49.334(\mathrm{x} 4)-24.651(\mathrm{x} 13)+21.197(\mathrm{x} 15)+$

$26.796(\mathrm{x} 5)+76.163(\mathrm{x} 16)+339.118(\mathrm{x} 2)+45.198(\mathrm{x} 11)$

$\begin{array}{lll}8 & 0.968 & 50.5\end{array}$

$\mathbf{Y}^{1}($ forearm+hand $)=-2837.067+66.216(x 4)-31.69(x 13)+$

$19.764(\mathrm{x} 15)+34.462(\mathrm{x} 5)+15.059(\mathrm{x} 1)+57.329(\mathrm{x} 11)+71.674(\mathrm{x} 16)+$ $400.319(\mathrm{x} 2)$

$9 \quad 0.967 \quad 65.4$

Wobbling Mass (WM)

$Y^{1}(\mathbf{a r m})=-3349.668+64.762(\mathrm{x} 1)+14.097(\mathrm{x} 9)-20.162(\mathrm{x} 8)+$

$71.605(\mathrm{x} 14)+36.312(\mathrm{x} 3)$

$\begin{array}{lll}10 & 0.964 \quad 127.1\end{array}$

$\mathbf{Y}^{1}($ forearm $)=-1492.793+22.131(\mathrm{x} 15)+100.012(\mathrm{x} 11)+4.948(\mathrm{x} 9)+$

$32.219(\mathrm{x} 5)+90.268(\mathrm{x} 16)$

$11 \quad 0.968 \quad 49.8$

$\mathbf{Y}^{\mathbf{1}}($ forearm + hand $)=-2500.727+127.402(\mathrm{x} 16)+29.627(\mathrm{x} 5)+$

$289.239(\mathrm{x} 2)+22.866(\mathrm{x} 15)+127.559(\mathrm{x} 11)+4.963(\mathrm{x} 9)+20.479(\mathrm{x} 7) \quad 12 \quad 0.963 \quad 69.4$

Note: Where: $\mathrm{x} 1=$ elbow circumference $(\mathrm{cm}), \mathrm{x} 2=$ height $(\mathrm{m}), \mathrm{x} 3=$ medial arm length $(\mathrm{cm}), \mathrm{x} 4=$ styloid circumference $(\mathrm{cm}), x 5=$ lateral forearm length $(\mathrm{cm}), \mathrm{x} 6=$ posterior forearm skinfold $(\mathrm{mm}), \mathrm{x} 7=$ medial forearm length $(\mathrm{cm}), \mathrm{x} 8=$ posterior arm skinfold $(\mathrm{mm}), \mathrm{x} 9=$ mass $(\mathrm{kg}), \mathrm{x10}=$ anterior arm skinfold $(\mathrm{mm})$, $\mathrm{x} 11=$ gender $(0$ for $\mathrm{F}, 1$ for $\mathrm{M}), \mathrm{x} 12=\operatorname{arm}$ breadth $(\mathrm{cm}), \mathrm{x} 13=$ medial forearm skinfold $(\mathrm{mm}), \mathrm{x} 14=\operatorname{arm}$ circumference $(\mathrm{cm}), \mathrm{x} 15=$ mid-forearm circumference $(\mathrm{cm}), \mathrm{x} 16=$ med/lat mid-forearm breadth $(\mathrm{cm})$. 
Table 4: Mean ( $\pm \mathrm{SD})$ predicted and actual masses (DXA) and mass error for the validation sample $(\mathrm{n}=24)$.

\begin{tabular}{lrrrrrrrrrr}
\hline \multicolumn{1}{c}{$\begin{array}{c}\text { Tissue and } \\
\text { Segment }\end{array}$} & $\begin{array}{c}\text { Predicted } \\
(\mathrm{g})\end{array}$ & \multicolumn{2}{c}{$\begin{array}{c}\text { Actual } \\
(\mathrm{g})\end{array}$} & $\begin{array}{c}\text { Error } \\
(\mathrm{g})\end{array}$ & \% Error & $\begin{array}{c}\text { RMS } \\
\text { Error }(\mathrm{g})\end{array}$ \\
\hline BMC & & & & & & & & & \\
$\quad$ Arm & 93.3 & $(21.3)$ & 90.7 & $(22.4)$ & 2.6 & $(12.5)$ & 4.3 & $(16.1)$ & 12.5 \\
$\quad$ Forearm & 73.8 & $(17.8)$ & 73.3 & $(18.2)$ & 0.6 & $(8.1)$ & 1.7 & $(13.4)$ & 7.9 \\
$\quad$ Forearm + hand & 99.5 & $(24.4)$ & 98.6 & $(24.8)$ & 0.9 & $(11.4)$ & 1.9 & $(13.9)$ & 11.2 \\
FM & & & & & & & & & \\
$\quad$ Arm & 548.0 & $(211.9)$ & 565.3 & $(229.7)$ & -17.3 & $(68.6)$ & 1.2 & $(20.9)$ & 69.4 \\
Forearm & 102.4 & $(48.4)$ & 95.3 & $(60.6)$ & 7.1 & $(29.9)$ & 15.5 & $(40.8)$ & 30.1 \\
Forearm + hand & 111.7 & $(48.2)$ & 104.7 & $(59.6)$ & 7.0 & $(28.8)$ & 12.5 & $(33.4)$ & 29.0 \\
LM & & & & & & & & & \\
Arm & 1717.2 & $(594.2)$ & 1686.5 & $(631.5)$ & 30.6 & $(141.2)$ & 3.2 & $(10.1)$ & 180.3 \\
Forearm & 868.2 & $(246.0)$ & 889.2 & $(269.4)$ & -21.0 & $(153.9)$ & 0.0 & $(22.4)$ & 152.1 \\
$\quad$ Forearm + hand & 1083.9 & $(323.7)$ & 1114.7 & $(344.1)$ & -30.8 & $(81.5)$ & -2.2 & $(9.7)$ & 85.5 \\
WM & & & & & & & & & \\
$\quad$ Arm & 2251.8 & $(593.0)$ & 2251.5 & $(589.1)$ & 0.3 & $(108.6)$ & 0.1 & $(5.3)$ & 112.3 \\
Forearm & 965.1 & $(239.7)$ & 979.2 & $(255.5)$ & -14.2 & $(57.8)$ & -1.0 & $(7.5)$ & 49.9 \\
$\quad$ Forearm + hand & 1201.0 & $(306.0)$ & 1213.9 & $(331.7)$ & -13.0 & $(91.9)$ & -0.4 & $(9.1)$ & 69.2 \\
\hline
\end{tabular}



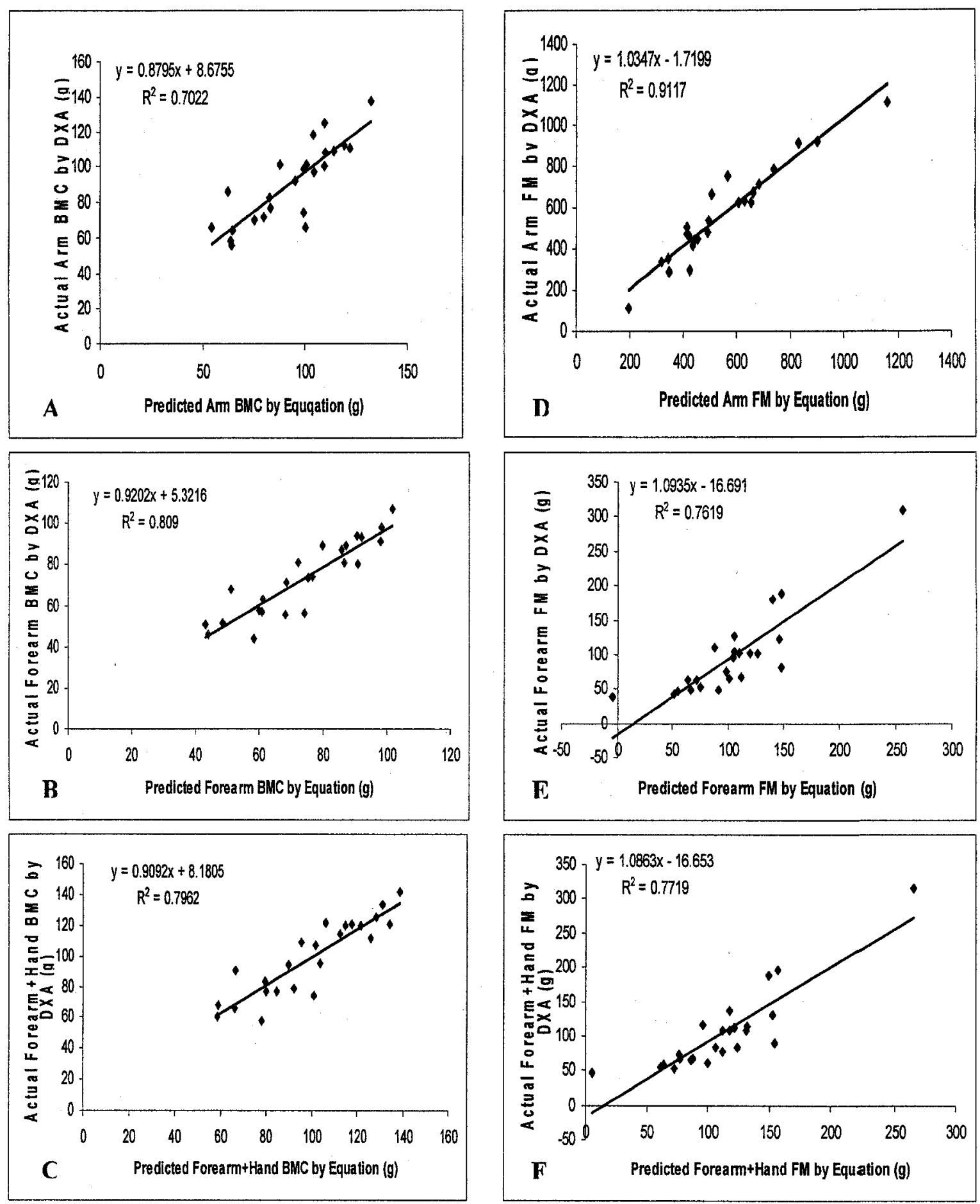

Figure 3: Relationships between predicted and measured tissue masses. BMC for the $\operatorname{arm}(A)$, forearm (B), and forearm + hand (C). FM for the arm (D), forearm (E), and forearm + hand $(\mathrm{F})$. (continued) 

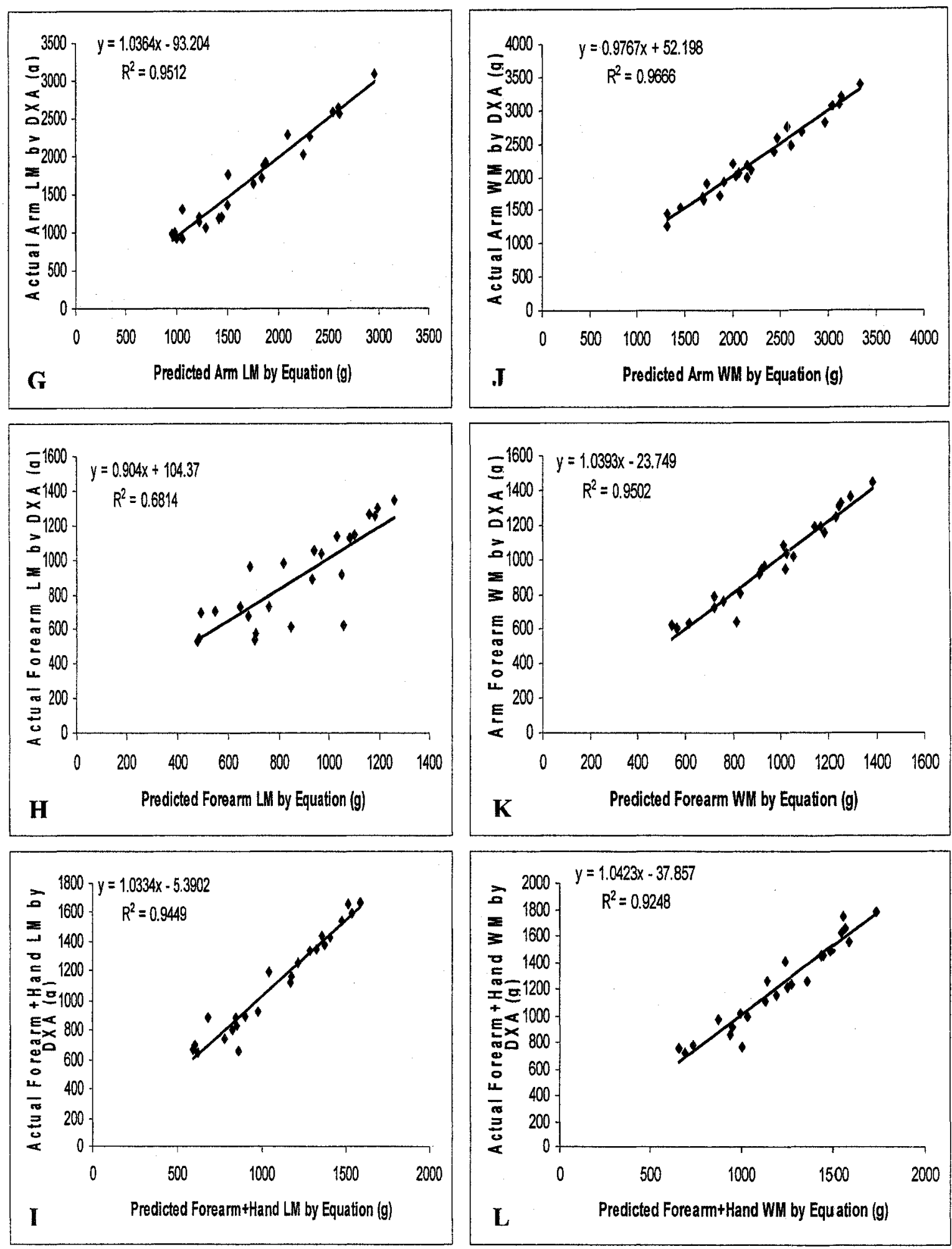

Figure 3: (Cont.): Relationships between predicted and measured tissue masses. LM for the $\operatorname{arm}(\mathrm{G})$, forearm $(\mathrm{H})$, and forearm + hand $(\mathrm{I})$. WM for the $\operatorname{arm}(\mathrm{J})$, forearm $(\mathrm{K})$, and forearm + hand $(\mathrm{L})$. 


\section{DISCUSSION}

\section{Summary of Results}

Twelve tissue mass prediction equations were produced for the upper limbs including those for bone mineral content, fat mass, lean mass, and wobbling mass for the arm, forearm, and forearm and hand segments. These predictive equations were developed from a series of anthropometric measurements including segment lengths, circumferences, breadths, and skinfolds. The generated equations resulted in a mean $\mathbf{R}^{2}$ of 0.91 across all tissue masses and segments, with the highest $R^{2}$ values attained for the lean and wobbling mass tissues. The equations were validated based on an independent sample. Mean \% errors and RMS errors ranged from $-2.2 \%$ and $15.5 \%$, and $7.9 \mathrm{~g}$ and $180.3 \mathrm{~g}$ for BMC of the forearm and arm LM, respectively. Scatter plots of predicted and actual segment tissue masses revealed high predictive power of the equations, resulting in $\mathrm{R}^{2}$ values ranging from 0.967 to 0.681 for $\mathrm{WM}$ of the arm and $\mathrm{LM}$ of the forearm, respectively.

\section{Comparison to the Literature}

The equations developed in the current study resulted in equivalent or greater explained variance and lower SEEs in general than those of Holmes et al. (2005) for the lower extremities (Table 5). The mass of the lower extremity segments is greater than the upper extremity segments, which may translate into greater measurement error, and therefore, less variance explained. It is also possible that the differences in error between the lower and upper extremities could be attributed to errors in landmark identification for the lower extremity segments in some cases. For example, to obtain the medial thigh measurement in the Holmes et al. (2005) study, it was necessary for participants to 
position and hold the end of the measuring tape over their pubis symphysis due to issues of modesty. Relying on the participants themselves increases the amount of between subject variability for this measure and will impact equation predictions.

Table 5: Comparison of explained variance $\left(\mathrm{R}^{2}\right)$ and standard errors (SEE) for each of the tissue mass segments between the current study and that of Holmes et al. (2005) for the lower extremities.

\begin{tabular}{llrrrrrrrr}
\hline Study & Segment & \multicolumn{2}{c}{ BMC } & \multicolumn{2}{c}{ FM } & \multicolumn{2}{c}{ LM } & \multicolumn{2}{c}{ WM } \\
& & $\mathrm{R}^{2}$ & $\mathrm{SEE}(\mathrm{g})$ & $\mathrm{R}^{2}$ & $\mathrm{SEE}(\mathrm{g})$ & $\mathrm{R}^{2}$ & $\mathrm{SEE}(\mathrm{g})$ & $\mathrm{R}^{2}$ & SEE(g) \\
\hline Holmes, & Thigh & 0.745 & 26.0 & 0.892 & 431.0 & 0.907 & 409.0 & 0.889 & 419.0 \\
et al., & Leg & 0.673 & 22.0 & 0.811 & 193.0 & 0.862 & 187.0 & 0.920 & 121.0 \\
2005 & Leg + & 0.737 & 24.0 & 0.785 & 200.0 & 0.872 & 209.0 & 0.925 & 139.0 \\
& foot & & & & & & & & \\
& Mean & $\mathbf{0 . 7 1 8}$ & $\mathbf{7 2 . 0}$ & $\mathbf{0 . 8 2 9}$ & $\mathbf{2 7 4 . 7}$ & $\mathbf{0 . 8 8 0}$ & $\mathbf{2 6 8 . 3}$ & $\mathbf{0 . 9 1 1}$ & $\mathbf{2 2 6 . 3}$ \\
& & & & & & & & & \\
Current & Arm & 0.866 & 9.4 & 0.870 & 79.7 & 0.942 & 154.8 & 0.964 & 127.1 \\
& Forearm & 0.862 & 7.7 & 0.861 & 22.5 & 0.968 & 50.5 & 0.968 & 49.8 \\
& Forearm & 0.854 & 10.7 & 0.860 & 22.4 & 0.967 & 65.4 & 0.963 & 69.4 \\
& + hand & & & & & & & & \\
& Mean & $\mathbf{0 . 8 6 1}$ & $\mathbf{9 . 3}$ & $\mathbf{0 . 8 6 3}$ & $\mathbf{4 1 . 5}$ & $\mathbf{0 . 9 5 9}$ & $\mathbf{9 0 . 2}$ & $\mathbf{0 . 9 6 5}$ & $\mathbf{4 8 . 8}$ \\
\hline
\end{tabular}

Though several methods of body composition estimation are available and have been used, DXA was selected to determine actual tissue masses for this study because it has the capacity to directly measure tissue masses in vivo. Tissue measurement from a living person avoids limitations such as the restricted availability of cadaver specimens (Dempster, 1955; Clarys et al., 1999), estimating mass discrepancies resulting from fluid loss (Grand, 1977; Clarys et al., 1984), or possible post-mortem tissue changes (Callaghan \& McGill, 1995; Querido, 1998). These limitations make it difficult to apply in vitro tissue data to the living population.

Many methods of in vivo tissue mass and body composition estimation, such as potassium counting, bioelectrical impedance, total body water, and even anthropometry and multi-component models, are only indirect methods and often times do not provide 
masses of several different tissue types (i.e. BMC, FM, LM, and WM) (Salamone, et al., 2000; Ball, Altena, \& Swan, 2004). Further, and perhaps more importantly, these types of methods do not provide segment specific tissue masses, but rather of the body as a whole (Van Loan, 1998; Ellis, 2000; Genton et al., 2002).

DXA does have its limitations; the leading one for this study was cost. However, despite the expense, DXA was still sought because of its ease of measurement, the reasonable time commitment for participants, and most importantly, the ability to attain the specific tissue mass type and segment data required for the purposes of the study. As convenient as DXA scanning seems, it is equally important to note that it has been shown to be a reliable and accurate method of data collection (Van Loan, 1998; Haarbo et al., 1991, Fuller et al., 1992). It has been compared to known masses and found to be a reliable source of measurement (GE Healthcare, 2004). DXA has also been found to be comparable to several other methods of body composition, including other imaging technologies (Gately et al., 2003; Wang et al., 2003). These two factors alone have served to justify its use in other, similar studies (Fuller et al., 1992; Van Loan, 1998; Holmes et al., 2005).

Other studies predicting body composition in living people have primarily focused on body density and anthropometric measures. Until recently, similar studies have not included the prediction of soft and rigid tissues independently (Holmes et al., 2005). Despite this limitation, previous studies showed strong predictive capacity for the masses they were targeting (Table 6), and indicate that estimating body composition using anthropometric measures can account for more variance and result in less error in general than when utilizing body density to estimate fat and fat free mass (FFM). Using indirect estimation of body density to produce actual tissue masses is most likely the cause of the 
greater error and lower predictability, compared to those equations based on direct measures from imaging technologies (Ball, Altena, \& Swan, 2004).

Table 6: A comparison of predicted body composition across studies using $\mathrm{R}^{2}$ and SEE (g) values.

\begin{tabular}{|l|l|c|c|c|c|c|c|}
\hline \multirow{2}{*}{ Study } & \multicolumn{1}{|c|}{ Prediction } & \multicolumn{2}{c|}{ Men } & \multicolumn{2}{c|}{ Women } & \multicolumn{2}{c|}{$\begin{array}{l}\text { Sexes } \\
\text { combined }\end{array}$} \\
\cline { 3 - 8 } & & $\begin{array}{l}\text { Mean } \\
\mathrm{R}^{2}\end{array}$ & $\begin{array}{l}\text { Mean } \\
\text { SEE }\end{array}$ & $\begin{array}{l}\text { Mean } \\
\mathrm{R}^{2}\end{array}$ & $\begin{array}{l}\text { Mean } \\
\text { SEE }\end{array}$ & $\begin{array}{l}\text { Mean } \\
\mathrm{R}^{2}\end{array}$ & $\begin{array}{l}\text { Mean } \\
\text { SEE }\end{array}$ \\
\hline Current Study & $\begin{array}{l}\text { BMC, FM, LM, WM of } \\
\text { upper extremities from } \\
\text { athropometric measures } \\
\text { \& DXA }\end{array}$ & --- & -- & -- & --- & 0.91 & $55.8 \mathrm{~g}$ \\
\hline $\begin{array}{l}\text { Holmes, et al. } \\
(2005)\end{array}$ & $\begin{array}{l}\text { BMC, FM, LM, WM of } \\
\text { lower extremities from } \\
\text { anthropometric } \\
\text { measures \& DXA }\end{array}$ & --- & -- & -- & --- & 0.84 & $198.3 \mathrm{~g}$ \\
\hline $\begin{array}{l}\text { Lean, Han, \& } \\
\text { Deurenberg } \\
\text { (1996) }\end{array}$ & $\begin{array}{l}\text { FM of the body from } \\
\text { anthropometric } \\
\text { measures \& body } \\
\text { density }\end{array}$ & 0.77 & $9.4 \mathrm{~g} / \mathrm{L}$ & 0.76 & $9.0 \mathrm{~g} / \mathrm{L}$ & -- & -- \\
\hline $\begin{array}{l}\text { Wilmore \& } \\
\text { Behnke } \\
\text { (1970) }\end{array}$ & $\begin{array}{l}\text { Body density \& LM } \\
\text { from anthropometric } \\
\text { measures \& hydrostatic } \\
\text { weighing }\end{array}$ & --- & --- & 0.72 & $6.9 \mathrm{~g} / \mathrm{L}$ & --- & --- \\
\hline $\begin{array}{l}\text { Wang et al. } \\
\text { (2003) }\end{array}$ & $\begin{array}{l}\text { Body BMC by total } \\
\text { body potassium \& MRI }\end{array}$ & --- & --- & -- & --- & 0.96 & $1500 \mathrm{~g}$ \\
\hline $\begin{array}{l}\text { Jackson \& } \\
\text { Pollock } \\
\text { (1978) }\end{array}$ & $\begin{array}{l}\text { Body density based on } \\
\text { anthropometric } \\
\text { measures }\end{array}$ & 0.91 & $7.6 \mathrm{~g}$ & -- & --- & --- & --- \\
\hline
\end{tabular}

BMC, as measured by Wang et al. (2003), and LM as measured by Wilmore and Behnke (1970), have very high predictive power. The high mean observed SEE value reported by Wang et al. (2003) for BMC exceeds that of the current study by a factor of approximately 27 times. However, these equations predict BMC for the whole body and not only for the upper limbs. Despite the high predictive ability of the total body potassium method (Wang et al., 2003), it is complex, and requires the use of expensive equipment. This makes it difficult to obtain and therefore an impractical method for 
many researchers (Haarbo et al., 1991). The BMC equations, presented in the current study, offer very high predictive power and are obtained by using simple anthropometric measures. The current equations are also specific to the upper extremities, which makes them unique to the literature.

Jackson and Pollock (1978) provide excellent body density prediction from anthropometric measures, with small associated error. It is possible to convert density to fatness, however, this can be problematic (Ball, Altena, \& Swan, 2004). Fat free mass can also be estimated but is influenced by error from the density to fatness conversion. Furthermore, the equations of Jackson and Pollock (1978) are unable to assess individual segments of the upper extremities, as well as soft and rigid tissue independently.

Potential Error Sources

Measurement Error

Factors that may influence the accuracy of anthropometric measurements include land marking of anatomical features, measurement accuracy, and measurement recording. Despite the potential for error in this type of research, several studies investigating similar anthropometric data collection procedures using anthropometry, have found it to be reliable, even between two or more investigators (Jackson, Pollock, \& Gettman, 1978; Klipstein-Grobusch, Georg, \& Boeing, 1997, Burkhart et al., 2007).

The accuracy of anatomical land marking is important in anthropometric measurement studies since taking measurements from incorrect locations will result in incorrect values. The subjectivity of such measurements is a major limitation (Fuller et al., 1991; Perini et al., 2005). To ensure maximal land marking accuracy in the current study, both investigators who took the measurements, were trained together and practiced 
together prior to data collection. For most measurements, bony land marks were used because of their accurate representation of the segment endpoints (eg. medial and lateral epicondyles of the humerus at the elbow), and because they are easy to locate.

The compressibility of underlying tissues may also contribute to significant measurement errors, particularly for circumference and breadth measurements. The magnitude of error associated with this depends on factors such as the type of measurement apparatus used (e.g. cloth measuring tape or callipers), as well as where on the segment the measurement is taking place (i.e. ends or mid segment where the bulk of the muscle resides). With circumference measurements, optimum tension in the measuring tape is important to ensure that the tape measure remains even all the way around the segment or target area. Both measurers in the current study were trained to be aware of this issue and to apply consistent tension and pressure between and within subjects.

The position of the body during measurement is also an important consideration. Whether the segment is flexed, neutral, or extended may affect the distribution of mass, and therefore the measurements associated with these areas. To avoid error associated with body position variance, all participants were instructed to remain in anatomical position while the measurements were being conducted. The use of a standardized posture helped to minimize this effect between measurers and participants.

Measurements in this study were recorded to the nearest millimetre. The two trained measurers had little difficulty with this level of precision. However, it is possible, given the pace at which they were measuring, that precision of this order may have contributed to some minor errors. 


\section{Arm Segmentation Method Using DXA}

Tissue masses from two different arm segments were analyzed for each upper extremity using the DXA software to determine if there was any difference in how well they could be predicted. The "whole shoulder" segment was defined by a vertical line directed just medial to the humeral head. The "humeral head" segment was defined proximally by a curved line that encompassed the head of the humerus. Significant differences were found between the masses from the two arm segments $(P<0.05)$. It was decided that the humeral head segmentation method would be used in the final equation development since it was a better representation of the anthropometrics used for prediction. For example, the most superior landmark considered was the acromion process. As such, the soft tissue that was encompassed by the whole shoulder segmentation method was not directly related to any of the measurements taken. To ensure that the most predictive segmentation method was selected, a few pilot regressions were run using both mass estimates. Greater variance was explained in the humeral head segment masses than those resulting from the whole shoulder segmentation approach.

\section{Bilateral Data Collapse}

Both the left and right upper extremities of participants were measured and segmented using the DXA software. ANOVAs revealed that significant differences between the sides occurred for all tissue masses in all segments and also in about half of the anthropometric measures $(P<0.05)$. Despite these differences, data from the two sides were averaged. The cause of the differences between the sides is not known. However, it is reasonable to assume that hand dominance may have played a significant 
role, since, on average, the right side contained $5 \%$ more mass than the left, across all participants. Considering the likelihood of a positive relationship existing between hand dominance and tissue mass, this compares reasonably to the $8-15 \%$ of right hand dominant people in the general population (Hardyck \& Petrinovih, 1977). Unfortunately, hand dominance was not recorded in the current study. Without these data it is not possible to verify the role that handedness may have played. Differences between the sides could also have been caused by other factors such as changes stemming from previous injuries. Averaging the anthropometrics and tissue masses from the left and right sides of the body was deemed reasonable since separate equations for the two sides would be less generalizable, and potentially cumbersome to use. Support for averaging the bilateral measurements is also provided by previous work (Heymsfield, McManus, Smith, Stevens, \& Nixon, 1982; Holmes et al., 2005)

\section{$\underline{\text { Sex Effects }}$}

Significant differences between the sexes were found for all but three of the segment tissue masses determined by DXA. Similar differences have been reported in the literature, whereby separate prediction equations were generated for each sex (Wilmore \& Behnke, 1970; Jackson \& Pollock, 1978; Lean, Han, \& Deurenberg, 1996), or sex was coded separately in the equations (Wang et al., 2003; Holmes et al., 2005) to account for the differences. However, in the current study, the initial attempts at equation generation revealed that, in most cases, sex was not getting stepped into the equations. Forcing sex into the equations had minimal effect; either slightly increasing the adjusted $R^{2}$, or in many cases, actually decreasing the $R^{2}$ and increasing the SEE. As a result, it was decided that sex would not be forced into the equations, and would be free to be stepped 
in if it explained enough variance. Five of the final equations code for sex, including those for arm FM, forearm LM, forearm and hand LM, forearm WM, and forearm and hand WM. Sex did not account for a significant amount of variance for the other segment tissue masses.

\section{Independent Variable Selection/Reduction}

The decision to eliminate some of the athropometric variables prior to entering them into the stepwise regression analyses, was based on several things, including improving the participant to variable ratio. It was decided first that variables would only be included in the equations that were specific to the segment measured. For example, forearm circumference was not entered into the analysis to generate the arm prediction equation. This automatically divided the variables into two groups, one for the arm segment and one for the forearm and forearm and hand segments. The elbow measurements, sex, height, and mass variables, were common to each. Next, the groups of variables were broken down further by measurement type. This separated each of the two variable groups into four, containing length, circumference, breadth, and skinfold measurements. Each of these four groups contained between two and five variables.

Elimination at this level was based on the relationship that the variables had with each other. Highly correlated variables were considered for elimination to help decrease the likelihood of multicollinearity problems. Decisions were also based on how reliable the anthropometric measurements were. A recent study by Burkhart, Arthurs, and Andrews (2007) assessed the between and within investigator reliability of the same anthropometric measures used for the current study. Reliability was measured in terms of intra-class correlation coefficients or ICCs (see Appendix Table A2). Similarly, how 
difficult the measurement was to obtain was also considered. Consideration was also given to what plane the measurements were in. For example, if several of the variables selected measured the medial aspect of a segment, then an anterior/posterior measurement might be given priority over another medial measurement, if other issues like multicollinearity did not preclude its consideration.

For some of the more difficult decisions about which variables would be deleted, trial regressions were run to determine which was more predictive. In some cases, both were kept. The process described above eliminated 11 variables from entering the regression analysis in total, leaving 11 variables for each of the arm, forearm, and forearm and hand segments that could have been selected. However, following the completion of the multiple linear regression analyses, it was found that two of the variables were not stepped into any of the equations. With the elimination of these variables, the resultant participant to variable ratios for the arm and forearm/forearm and hand segments were 8.4:1 and 7:1, respectively. These ratios exceed the minimum standard of $4: 1$ suggested by Kerlinger and Pedhazer (1973). Holmes et al. (2005) cited a 4:1 ratio for the lower extremity equations they developed.

\section{Assumptions of Multiple Linear Regression}

Multiple linear regression assumes that there are no outliers present in the data. Only one variable, elbow circumference, was found to have one case displaced from the rest. The recorded value of this variable for the one subject was $14.7 \mathrm{~cm}$, with the next smallest value being $21.3 \mathrm{~cm}$. It is not possible that $14.7 \mathrm{~cm}$ is a true measure of elbow circumference for the population tested. Therefore, a recording error was likely. The outlier was replaced with the mean left elbow circumference measurement of the group 
$(25.7 \mathrm{~cm})$. This value, more favourably and reasonably, compares with the right elbow circumference measurement of $22.5 \mathrm{~cm}$. Since significant differences were found bilaterally for many variables, it was decided not to replace the left value with that of the right.

Absence of multicollinearity is also an assumption that must be met for accurate multiple regression. After the original regression equations were generated, it was found that four of the equations violated this assumption. To correct this, offending variables were omitted one at a time to note the effects of each. For arm LM and WM, new equations were produced without the mid-arm breadth (A-P) measurement. For the WM of the forearm, the removal of both elbow and styloid circumference measurements was necessary. The equation for WM of the forearm and hand was corrected by simply omitting styloid circumference. Sometimes, by omitting these variables, other variables were stepped into the equation to account for the variance attributed to the omitted variable. Other times, the equation stayed the same, but accounted for a little less variance. No multicollinearity violations existed following equation modification.

\section{Prediction Error}

Holmes et al. (2005) reported that most of the equations they generated for the lower extremities overestimated the actual tissue masses, with the exception of FM of the thigh, and leg and foot segments. In comparison, the current equations overestimated seven of the tissue masses, while five were underestimated (Table 4). However, in all cases, the differences between the actual and predicted values were found not to be statistically significant $(P<0.05)$. 
The least amount of error was associated with the lean and wobbling masses, despite how large the masses were in magnitude. Percent errors in general were very low, ranging from $2.2 \%$ to approximately $4 \%$ for the arm and forearm segments, respectively. These values are in line with those previously reported in the literature for body composition equations (Jackson \& Pollock, 1977; Holmes et al., 2005).

Functional Significance and Application

The focus of this study was to provide simple, easy to use, and cost-effective equations to predict tissue masses of three segments of the upper extremities in living subjects. Twelve equations were produced which yielded high adjusted $R^{2}$ values and relatively low SEE values.

It is anticipated that the primary use of these equations will be by researchers in biomechanics and associated health related fields. More accurate predications of segment tissue masses will enable researchers to establish biomechanical models that more realistically represent the dynamic motion and responses to human movements.

The simplicity of the measurements allows most people, with the proper apparatus, to predict BMC, FM, LM, and WM. The only equipment necessary is a measuring tape, for the lengths and circumferences, and callipers for breadths and skinfolds. As such, team coaches and fitness trainers working in gymnasia or similar facilities, may find this data particularly useful since they are interested in quantifying body composition of their players and clients. Healthcare professionals may also like to use the equations as a means of diagnosing a problem, if access to more expensive imaging technologies is not possible (e.g. BMC in osteoporosis patients). 


\section{Limitations}

The most significant limitation of the current study is the number of participants. It has been suggested that a good rule of thumb, at an alpha level of 0.05 , is that the number of participants be $\geq 50+8 m$, where $m$ is the number of IVs (Tabachnick \& Fidell, 2001). For this study, that would require 138 participants for equation generation. The current study had 76. However, despite this limitation, other studies have cited and used smaller participant to IV ratios, which the current study has exceeded (Kerlinger \& Pedhazer, 1973; Holmes et al., 2005). Further, the high degree of explained variance for each of the generated equations, along with the corresponding small SEEs, suggest that highly predictive equations were produced.

Having the anthropometric measurements taken by two people may have contributed to a systematic bias between the left and right side measurements. Significant differences between the measurements for the left and right sides of the body did exist in the current study. However, several studies have shown high measurement reliability within and between measurers (Jackson, Pollock, \& Gettman, 1978; Klipstein-Grobusch, Georg, \& Boeing, 1997). In particular, work by Burkhart et al. (2007), using the same anatomical landmarks and measurements, showed very high reliability between measurers, with intra-class correlation coefficients (ICCs) ranging from 0.59 to 0.99 for all measurements. Some between measurer differences may be attributed to discrepancies in anatomical land mark identification, but no systematic bias to this end, was detected during training or during data collection.

The generalizability of the equations is also somewhat limited due to the restricted sample they were generated from (i.e young, healthy adults). Body composition has been found to fluctuate with factors such as age (Baumgartner, Stauber, McHugh, Ko ehler, 
Garry, 1995; Baumgartner, 2000), sex (Daniels, Khoury, \& Morrison, 1997), and health status (Poehlman, Toth, \& Gardner, 1995). As a result, those that would like to utilize the equations for a specific application, need to keep the characteristics of the generation sample in mind.

Future Directions

The reliability of the segmentation approach used in this study needs to be quantified for multiple users and for multiple trials. Two segmentation trials were performed in this current study to provide a starting point for this analysis.

Prediction equations should be developed for more extreme body types, including people like body builders and the obese. The current equations, and those by Holmes et al. (2005), were developed for healthy, young adults. Separate equations for older adults and children would be extremely beneficial to encapsulate differences in body composition based on age. Being able to model the effects of wobbling mass, for example, is contingent on knowing how much wobbling mass there is in a given segment, for a given individual.

Future efforts should also be focused on the development of predictive equations for other segments of the body, including the trunk, neck and head regions. This however, is only a first step. Developing biomechanical models that incorporate both soft and rigid tissue components requires, in addition to knowledge of the tissue mass magnitudes, knowledge of how the tissue mass for each segment is distributed. Three dimensional imaging technologies will need to be utilized in order to provide this type of information, as DXA is limited to assessments of mass in two dimensions by the segmentation software that is provided by the manufacturers. 


\section{CONCLUSION}

The results of this study indicate that simple anthropometric measurements can be used to accurately predict bone mineral content, fat mass, lean mass, and wobbling mass of the arm, forearm, and forearm and hand segments of young healthy adults. These equations will allow participant-specific tissue mass information to be determined for the upper extremities without the use of expensive imaging technologies, such as DXA. They will also help to provide a better understanding of the effects that wobbling mass tissues have on the response of the upper extremities in dynamic situations, by enabling more accurate tissue models to be developed. The use of such models by researchers in allied health disciplines and engineering will hopefully result in an improved understanding of how we respond to external influences, such as impacts to the outstretched hands following a forward fall. This knowledge could translate into more effective injury prevention strategies that can be utilized to improve the health of people in a variety of activities. 
Table A1: Description of lower extremity measurements taken bilaterally and recorded to the nearest millimetre, where (M-L) and (A-P) indicates that the measurements were taken in the medial-lateral and anterior-posterior directions, respectively. These measurements are identical to those used by Holmes et al. (2005).

\begin{tabular}{|c|c|}
\hline Variable & Measurement Descriptions \\
\hline Lateral Thigh Length & $\begin{array}{l}\text { Distance between the superior iliac crest and the lateral } \\
\text { aspect of the tibial plateau }\end{array}$ \\
\hline Medial Thigh Length & $\begin{array}{l}\text { Distance between the anterior level of the pubis } \\
\text { symphysis and the medial aspect of the tibial plateau }\end{array}$ \\
\hline Proximal Mid-Thigh Length & $\begin{array}{l}\text { Distance between the anterior level of the pubis } \\
\text { symphysis and the medial aspect of the femur at the } \\
\text { level of maximum circumference midway between the } \\
\text { superior iliac crest and the tibial plateau }\end{array}$ \\
\hline Lateral Leg Length & $\begin{array}{l}\text { Distance between the lateral aspect of the tibial plateau } \\
\text { and the inferior base of the lateral malleoli. }\end{array}$ \\
\hline Medial Leg Length & $\begin{array}{l}\text { Distance between the lateral aspect of the tibial plateau } \\
\text { and the inferior base of the lateral malleoli }\end{array}$ \\
\hline Proximal Mid-Leg Length & $\begin{array}{l}\text { Distance between the medial aspect of the tibial plateau } \\
\text { and the medial aspect of the tibia at the level of } \\
\text { maximum calf circumference midway between the tibial } \\
\text { plateau and the malleoli }\end{array}$ \\
\hline Upper Thigh Circumference & $\begin{array}{l}\text { Distance around the femur and overlying tissue just } \\
\text { inferior to the gluteal fold }\end{array}$ \\
\hline Mid-Thigh Circumference & $\begin{array}{l}\text { Maximum distance around the femur and overlying } \\
\text { tissues midway between the superior iliac crest and the } \\
\text { tibial plateau }\end{array}$ \\
\hline Knee Circumference & $\begin{array}{l}\text { Distance around the outmost projections of the tibia and } \\
\text { overlying tissues }\end{array}$ \\
\hline Mid-Calf Circumference & $\begin{array}{l}\text { Maximal distance around the calf midway between the } \\
\text { tibial plateau and the malleoli }\end{array}$ \\
\hline Ankle Circumference & $\begin{array}{l}\text { Distance around the tibia and fibula, and overlying } \\
\text { tissues just superior to the malleoli }\end{array}$ \\
\hline Malleoli Circumference & $\begin{array}{l}\text { Distance around the most lateral projections and } \\
\text { overlying tissue of the tibia and fibula }\end{array}$ \\
\hline Upper Thigh Breadth (A-P) & $\begin{array}{l}\text { Distance across the femur and overlying tissues just } \\
\text { inferior to the gluteal fold }\end{array}$ \\
\hline Mid-Thigh Breadth (M-L) & $\begin{array}{l}\text { Distance across the femur and overlying tissue at the } \\
\text { level of maximum circumference midway between the } \\
\text { superior iliac crest and the tibial plateau }\end{array}$ \\
\hline Mid-Thigh Breadth (A-P) & $\begin{array}{l}\text { Distance across the femur and overlying tissue at the } \\
\text { level of maximum circumference midway between the } \\
\text { superior iliac crest and the tibial plateau }\end{array}$ \\
\hline Knee Breadth & $\begin{array}{l}\text { Distance between the outmost projections and overlying } \\
\text { tissue of the tibia at the level of the tibial plateau }\end{array}$ \\
\hline Mid-Calf Breadth (M-L) & $\begin{array}{l}\text { Distance across the tibia and overlying tissues at the } \\
\text { level of maximum calf circumference }\end{array}$ \\
\hline
\end{tabular}




\begin{tabular}{|l|l|}
\hline Mid-Calf Breadth (A-P) & $\begin{array}{l}\text { Distance across the tibia and overlying tissues at the } \\
\text { level of maximum calf circumference }\end{array}$ \\
\hline Ankle Breadth & $\begin{array}{l}\text { Distance between the lateral aspects of the tibia and } \\
\text { fibula and overlying tissues just superior to the malleoli }\end{array}$ \\
\hline Malleoli Breadth & $\begin{array}{l}\text { Distance between the most lateral projections and } \\
\text { overlying tissues of the tibia and fibula }\end{array}$ \\
\hline Medial Mid-Calf Skinfold & $\begin{array}{l}\text { Vertical fold on the medial aspect of the calf at the level } \\
\text { of maximum circumference with the subject's weight } \\
\text { placed on the opposite leg }\end{array}$ \\
\hline Posterior Mid-Calf Skinfold & $\begin{array}{l}\text { Vertical fold on the posterior aspect of the calf at the } \\
\text { level of maximum circumference with the subject lying } \\
\text { prone }\end{array}$ \\
\hline Anterior Mid-Thigh Skinfold & $\begin{array}{l}\text { Vertical fold on the anterior aspect of the thigh at the } \\
\text { level of maximum circumference midway between the } \\
\text { superior iliac crest and the tibial plateau with the } \\
\text { subject's weight placed on the opposite leg }\end{array}$ \\
\hline Posterior Mid-Thigh Skinfold & $\begin{array}{l}\text { Vertical fold on the posterior aspect of the thigh at the } \\
\text { level of maximum circumference midway between the } \\
\text { gluteal fold and the popliteal fossa with the subject } \\
\text { lying prone }\end{array}$ \\
\hline
\end{tabular}


Table A2: Mean (SD) measurements for the upper extremity by site (cm), measurement differences between and within-measurers $(\mathrm{cm})$, and between and within-measurer reliability coefficients (ICCs). Significant differences $(p<0.05)$ between-measurers and between sexes are indicated with $\mathrm{a}^{*}$ and $\uparrow$, respectively (Burkhart et al., 2007).

\begin{tabular}{|c|c|c|c|c|c|c|c|}
\hline \multirow[t]{2}{*}{ Measures } & \multicolumn{3}{|c|}{ Mean Measurements $(\mathrm{cm})$} & \multicolumn{2}{|c|}{ Measurement Differences $(\mathrm{cm})$} & \multicolumn{2}{|c|}{ ICCs } \\
\hline & Overall & Male $(n=25)$ & Female $(n=25)$ & Between & Within & Between & Within \\
\hline \multicolumn{8}{|l|}{ Upper Extremity } \\
\hline \multicolumn{8}{|l|}{ Lengths } \\
\hline Lateral arm & $* 30.28(1.14)$ & $\dagger 31.1(2.5)$ & $29.5(1.6)$ & 1.45 & 0.21 & 0.84 & 0.88 \\
\hline Medial arm & $* 24.4(0.4)$ & $24.7(1.9)$ & $24.1(1.4)$ & 1.28 & 0.21 & 0.85 & 0.80 \\
\hline Proximal mid-arm & $10.6(0.12)$ & $10.7(1.5)$ & $10.5(2.1)$ & 0.52 & 0.21 & 0.65 & 0.66 \\
\hline Lateral forearm & $* 25.8(1.5)$ & $\uparrow 26.9(1.9)$ & $24.7(1.5)$ & 1.07 & 0.10 & 0.88 & 0.87 \\
\hline Medial forearm & $25.7(1.2)$ & $\dagger 25.6(1.8)$ & $24.0(1.4)$ & 0.13 & 0.28 & 0.89 & $0: 82$ \\
\hline Proximal mid-forearm & $* 11.4(0.8)$ & $\dagger 12.0(1.9)$ & $10.9(1.7)$ & 1.38 & 0.19 & 0.70 & 0.81 \\
\hline \multicolumn{8}{|l|}{ Circumferences } \\
\hline Upper arm & *32.4(3.0) & $\uparrow 34.5(3.2)$ & $30.4(2.9)$ & 0.87 & 0.26 & 0.94 & 0.90 \\
\hline Mid-arm & *31.2(4.8) & $\uparrow 34.6(3.2)$ & $27.8(2.9)$ & 0.48 & 0.09 & 0.94 & 0.92 \\
\hline Elbow & $26.3(2.7)$ & $+28.2(1.7)$ & $24.3(1.5)$ & 0.15 & 0.04 & 0.99 & 0.99 \\
\hline Mid-forearm & $* 24.0(2.9)$ & $\uparrow 26.0(2.0)$ & $21.9(1.8)$ & 1.28 & 0.19 & 0.93 & 0.96 \\
\hline Wrist & ${ }^{*} 16.9(1.7)$ & $\uparrow 18.2(1.0)$ & $15.8(1.0)$ & 0.13 & 0.02 & 0.99 & 0.99 \\
\hline Styloid & $16.7(1.6)$ & $\dagger 17.8(0.9)$ & $15.6(0.7)$ & 0.09 & 0.06 & 0.99 & 0.98 \\
\hline \multicolumn{8}{|l|}{ Breadths } \\
\hline Upper arm & $* 10.4(0.7)$ & $\dagger 10.9(1.6)$ & $9.9(1.2)$ & 1.99 & 0.18 & 0.59 & 0.87 \\
\hline Mid-arm (M-L) & $* 8.3(0.8)$ & $\uparrow 8.9(0.9)$ & $7.7(0.9)$ & 0.24 & 0.09 & 0.95 & 0.92 \\
\hline Mid-arm (A-P) & $10.1(1.3)$ & $\dagger 10: 9(1.6)$ & $9.1(1.0)$ & 0.05 & 0.06 & 0.95 & 0.92 \\
\hline Elbow & $9.1(0.2)$ & $9.2(0.8)$ & $8.9(7.1)$ & 0.11 & 0.65 & 0.86 & 0.93 \\
\hline Mid-forearm (M-L) & $8.0(1.0)$ & $+8.7(0.8)$ & $7.2(0.6)$ & 0.17 & 0.03 & 0.94 & 0.93 \\
\hline Mid-forearm (A-P) & $* 7.6(2.3)$ & $+9.2(0.6)$ & $5.9(0.6)$ & 0.29 & 0.07 & 0.92 & 0.91 \\
\hline Wrist & $* 5.8(0.5)$ & $\div 6.2(0.4)$ & $5.5(0.4)$ & 0.23 & 0.04 & 0.95 & 0.94 \\
\hline Styloid & $* 5.8(0.5)$ & $\uparrow 6.1(0.6)$ & $5.4(0.4)$ & 0.15 & 0.07 & 0.78 & 0.91 \\
\hline \multicolumn{8}{|l|}{ Skinfolds } \\
\hline Medial forearm & $0.6(0.2)$ & $+0.5(0.1)$ & $0.7(0.2)$ & 0.04 & 0.01 & 0.96 & 0.95 \\
\hline Posterior forearm & $0.6(0.1)$ & $0.5(0.2)$ & $0.7(0.2)$ & 0.03 & 0.01 & 0.89 & 0.91 \\
\hline Anterior arm & $* 0.8(0.3)$ & $\uparrow 0.6(0.3)$ & $1.0(0.4)$ & 0.25 & 0.04 & 0.87 & 0.88 \\
\hline Posterior arm & ${ }^{*} 1.5(0.4)$ & $+1.2(0.5)$ & $1.8(0.6)$ & 0.25 & 0.01 & 0.96 & 0.96 \\
\hline
\end{tabular}




\section{References}

Amis, A. A. \& Miller, J. H. (1995). The mechanisms of elbow fractures: an investigation using impact tests in vitro. Injury, 26(3),163-168.

Ball, S. D., Altena, T. S., \& Swan, P. D. (2004). Comparison of anthropometry to DXA: a new prediction equation for men. European Journal of Clinical Nutrition, 58, 15251531.

Blake, G. M., McKeeney, D. B., Chhaya, S. C., Ryan, P. J., \& Fogelman, I. (1992). Dual energy x-ray absorptiometry: the effects of beam hardening on bone density measurements. Medical Physics, 19(2), 459-465.

Bobbert, M. F., Yeadon, M. R., \& Nigg, B. N. (1992). Mechanical analysis of the landing phase in heel-toe running. Journal of Biomechanics, 25(3), 223-234.

Bracco, D., Thiébaud, D., Chioléro, R. L., Landry, M., Burckhardt, P., \& Schutz, Y. (1996). Segmental body composition assessed by bioelectrical impedance analysis and DEXA in humans. Journal of Applied Physiology, 81(6), 2580-2587.

Baumgartner, R. N. (2000). Body composition in health aging. Annals New Yourk Academy of Sciences, 904, 437-448.

Baumgartner, R. N., Stauber, P. M., McHugh, D., Koehler, K. M., \& Garry, P.J. (1995). Cross-sectional age differences in body composition in persons 60+ years of age. Journals of Gerontology Series A: Biological Sciences and Medical Sciences, 50(6), M307-M316.

Braune, W. \& Fischer, O. (1889). Über den schwerpunkt des menschlichen körpers, mit rücksicht auf die aüsrustung des deutschen infanteristen. (The center of gravity of the human body as related to the equipment of the German infantry), Gesselschaft der Wisenschafiten, 26, 561-672. In W. M. Korgman \& F. E. Johnston (Eds), Human mechanics: four monographs abridged, (1963). AMRL-TDR-63-123. Wright-Patterson Air Force Base, Ohio.

Bray, G. A., Greenway, F. L., Molitch, M. E., Dahms, W. T., Atkinison, R. L., \& Hamilton, K. (1978). Use of anthropometric measures to assess weight loss. The American Journal of Clinical Nutrition, 31(5), 769-773.

Burkhart, T. A., Arthurs, K. L., \& Andrews, D. M. (2007). Reliability of upper and lower extremity anthropometric measurements and the effect on tissue mass prediction. Proceeding of 2007 American Society of Biomechanics (ASB) Conference, Palo Alto, California. 
Callaghan, J. P. \& McGill, S. M. (1995). Frozen storage increases the ultimate compressive load of porcine vertebrae. Journal of Orthopaedic Research, 13(5), 809-812.

Chumlea, W. C. \& Guo, S. (1994). Bioelectrical impedance and body composition: present status and future directions. Nutrition Reviews, 52(4), 123-135.

Clarys, J. P. \& Marfell-Jones, M. J. (1986). Anatomical segmentation in humans and the prediction segmental masses from intra-segmental anthropometry. Human Biology, 58(5), 771-782.

Clarys, J. P. \& Marfell-Jones, M. J. (1994). Soft tissue segmentation of the body and fractionation of the upper and lower limbs. Ergonomics, 37(1), 217- 229.

Clarys, J. P., Martin, A. D., \& Drinkwater, D. T. (1984). Gross tissue weights in the human body by cadaver dissection. Human Biology, 56(3), 459-473.

Clarys, J. P., Martin, A. D., Marfell-Jones, M. J., Janssens, V., Caboor, D., \& Drinkwater, D. T. (1999). Human body composition: A review of adult dissection data. American Journal of Human Biology, 11(2), 167-174.

Culebras, J. M. \& Moore, F. D. (1977). Total body water and the exchangeable hydrogen I. Theoretical calculation of nonaqueous exchangeable hydrogen in man. American Journal of Physiology, 232(1), 54-59.

Daniels, S. R., Khoury, P. R., \& Morrison, J. A. (1997). The utility of body mass index as a measure of body fatness in children and adolescents: differences by race and gender. Pediatrics, 99(6), 804-807.

Dempster, W. T. (1955). Space requirements of the seated operator. WADC TR 55-159. Wright-Patterson Air Force Base, Ohio.

Dempster, W. T. \& Gaughran, G. R. L. (1955). Properties of body segments based on size and weight. American Journal of Anatomy, 120(1), 33-54.

Deurenberg, P. (1996). Limitations of the bioelectrical impedance method for the assessment of body fat in severe obesity. The American Journal of Clinical Nutrition, 64(3 Suppl), 449S-452S.

Edwards, D. A. W., Hammond, W. H., Healy, M. J. R., Tanner, J. M., \& Whitehouse, R. H. (1955). Design and accuracy of callipers for measuring subcutaneous tissue thickness. British Journal of Nutrition, 9(2), 133-143.

Ellis, K. J. (2000). Human body composition: In vivo methods. Physiological Reviews, $80(2), 649-680$. 
Farley, C. T. \& González, O. (1996). Leg stiffness and stride frequency in human running. Journal of Biomechanics, 29(2), 181-186.

Feng, Y. J., Chen, W. R., Sun, T.P., Duan, S. Y., Jia, B.S., \& Zhang, H. L. (2002). Estimated cosmic radiation doses for flight personnel. Space Medicine Medical Engineering, 15(4), 265-269.

Ferris, D. P \& Farley, C. T. (1997). Interaction of leg stiffness and surface stiffness during human hopping. Journal of Applied Physiology, 82(1), 15-21.

Forbes, G. B. (1987). Lean body mass-body fat interrelationships in humans. Nutrition reviews, 5(8), 225-231.

Fuller, N. J., Jebb, S. A., Goldberg, G. R., Pullicino, T., Adams, C., Cole, T. J., \& Elia M. (1991). Inter-observer variability in the measurement of body composition. European Journal of Clinical Nutrition, 45(1), 43-49.

Fuller, N. J., Laskey, M. A., \& Elia, M. (1992). Assessment of the composition of major body regions by dual-energy $\mathrm{x}$-ray absorptiometry (DEXA), with special reference to limb muscle mass. Clinical Physiology, 12(3), 253-266.

Gately, P. J., Radley, D., Cooke, C. B., Carroll, S., Oldroyd, B., Truscott, J. G., Coward, W. A., \& Wright A. (2003). Comparison of body composition methods in overweight and obese children. Journal of Applied Physiology, 95, 2039-2046.

General Electric Healthcare (2004). Lunar Prodigy Advance Specification Manual.

Genton, L., Didier, H., Kyle, U. G., \& Pichard, C. (2002). Dual-energy x-ray absorptiometry and body composition: differences between devices and comparison with reference methods. Nutrition, 18(1), 66-70.

Gittoes, M. J. R., Brewin, M. A., \& Kerwin, D. G. (2006). Soft tissue contributions to impact forces simulated using a four-segment wobbling mass model of forefootheel landings. Human Movement Science, 25(6), 775-787.

Grand, T. I. (1977). Body weight: Its relation to tissue composition, segment distribution, and motor function. American Journal of Physical Anthropology, $47(2), 211-240$.

Grinspoon, S., Corcoran, C., Lee, K., Burrows, B., Hubbard, J., Katznelson, L., Walsh, M., Guccione, A., Cannan, J., Heller, H., Basgoz, N., \& Klibanski, A. (1996). Loss of lean body and muscle mass correlates with androgen levels in hypogonadal men with acquired immunodeficiency syndrome and wasting. Journal of Clinical Endocrinology and Metabolism, 81(11), 4051-4058.

Grinspoon, S., Corcoran, C., Askari, H., Schoenfeld, D., Wolf, L., Burrows, B., Walsh, M., Hayden, D., Parlman, K., Anderson, E., Basgoz, N., \& Klibanski, A. (1998). 
Effects of androgen administration in men with the AIDS wasting syndrome. Annals of Internal Medicine, 129(1), 18-26.

Gruber, K., Ruder, H., Denoth, J., \& Schneider, K. (1998). A comparative study of impact dynamics: wobbling mass model versus rigid body models. Journal of Biomechanics, 31(5), 439-444.

Haarbo, J., Gotfredsen, A., Hassager, C., \& Christiansen, C. (1991). Validation of body composition by dual energy x-ray absorptiometry (DEXA). Clinical Physiology, 11(4), 331-341.

Hanavan, E. P. (1964). A mathematical model of the human body. Wright-Patterson Air Force Base, Ohio. (AMRL-TR-64-102).

Hardyck, C., \& Petrinovich, L. F. (1977). Left-handedness. Psychological Bulletin, 84, $385-404$.

Heymsfield, S. B., McManus, C., Smith, J., Stevens, V., \& Nixon, D. W. (1982). Anthropometric measurement of muscle mass: revised equations for calculating bone-free arm muscle area. The American Journal of Clinical Nutrition, 36, 680690.

Holmes J. D., Andrews, D. M., Durkin, J. L., \& Dowling, J. J. (2005). Predicting in vivo soft tissue masses of the lower extremity using segment anthropometric measures and DXA. Journal of Applied Biomechanics, 21 (4), 371-382.

Hsiao, E. T. \& Robinovitch, S. N. (1998). Common protective movements govern unexpected falls from standing height. Journal of Biomechanics, 31(1), 1-9.

Ioannidou, E., Padilla, J., Wang, J., Heymsfield, S. B., Thornton, J. C., Horlick, M., \& Gallagher, D. (2003). Pencil-beam versus fan-beam dual-energy x-ray absorptiometry comparisons across four systems: appendicular lean soft tissue. Acta Diabetologica, 40(1), S83-S85.

Jackson, A. S., \& Pollock, M, L. (1977). Prediction accuracy of body density, lean body weight, and total body volume equations. Medicine and Science in Sports, 4, 197 201.

Jackson, A. S., \& Pollock, M. L. (1978). Generalized equations for predicting body density of men. British Journal of Nutrition, 40, 497-504.

Jackson, A. S., Pollock, M. L., \& Gettman, L. R. (1978). Intertester reliability of selected skinfold and circumference measurements and percent fat estimates. Research Quarterly, 49(4), 546-551.

Jebb, S. A., Goldberg, G. R., Jennings, G., \& Elia, M. (1995). Dual-energy x-ray absorptiometry measurements of body composition: effects of depth and tissue 
thickness, including comparisons with direct analysis. Clinical Science, 88(3), 319324.

Kemerink, G. J., DeHaan, M. W., Vasbinder, G. B. C., Frantzen, M. J., Schultz, F. W., Zoetelief, J., Jansen, J. T. H. M., \& VanEngelshoven, J. M. A. (2003). The effect of equipment set up on patient radiation dose in conventional and CT angiography of the renal arteries. The British Journal of Radiology, 76(909), 625-630.

Kerlinger, F. N. \& Pedhazar, E. S. (1973). Multiple regression in behavioural research. New York: Holt, Reinhart, \& Winston.

Kline, R. B. (1998). Principles and practice of structural equation modeling. New York: Guilford.

Klipstein-Grobusch, K., Georg, T., \& Boeing H. (1997). Interviewer variability in anthropometric measurements and estimates of body composition. International Journal of Epidemiology, 26(1), 174-180.

Kohrt, W. M. (1998). Preliminary evidence that DEXA provides an accurate assessment of body composition. Journal of Applied Physiology, 84(1), 372-377.

Kotler, D. P., Burastero, S., Wang, J., \& Pierson, R. N. Jr. (1996). Prediction of body cell mass, fat-free mss, and total body water with bioelectrical impedance analysis: effects of race, sex, and disease. The American Journal of Clinical Nutrition, 64(3 Suppl), 489S-497S.

Lean, M. E. J., Han, T. S., \& Deurenberg, P. (1996). Predicting body composition by densitometry from simple anthropometric measurements. American Journal of Clinical Nutrition, 63, 4-14.

Ley, C., Lees, B., \& Stevenson, J. C. (1992). Sex- and menopause-associated changes in body-fat distribution. The American Journal of Clinical Nutrition, 55(5), 950-954.

Liu, W. \& Nigg, B. M. (2000). A mechanical model to determine the influence of masses and mass distribution on the impact force during running. Journal of Biomechanics, $33(2), 219-224$.

Lohman, T. G., \& Going, S. B. (1993). Multicomponent models in body composition research: opportunities and pitfalls. In K.J. Ellis \& J. D. Eastman (Eds.), Human body composition (pp. 53-58). New York: Plenum Press.

Lukaski, H. C., Johnson, P. E., Bolonchuck, W. W., \& Lykken, G. E. (1985). Assessment of fat-free mass using bioelectrical impedance measurements of the human body. The American Journal of Clinical Nutrition, 41(4), 810-817.

Made, C., Elmqvist, L. G., (2004). A 10 year study of snowboard injuries in Lapland Sweden. Scandinavian Journal of Medicine and Science in Sports, 14(2), 128-133. 
Martin, A. D., Daniel, S., Clarys, J. P., \& Marfell-Jones, M. J. (2003). Cadaver-assessed validity of anthropometric indicators of adipose tissue distribution. International Journal of Obesity, 27, 1052-1058.

Martin, A. D., Spenst, L. F., Drinkwater, D. T., \& Clarys, J. P. (1989). Anthropometric estimation of muscle mss in men. Medicine and Science in Sports and Exercise, 22(5), 729-733.

Mazess, R. B., Barden, H. S., Bisek, J. P., \& Hanson, J. (1990). Dual-energy x-ray absorptiometry for total-body and regional bone-mineral and soft-tissue composition. The American Journal of Clinical Nutrition, 51(6), 1106-1112.

Midha, A., Howell, L. L. \& Norton, T. W. (2000). Limit positions of compliant mechanisms using the pseudo-rigid-body model concept. Mechanism and Machine Theory, 35(1), 99-115.

Mueller, W. H., \& Malina, R. M. (1987). Relative reliability of circumferences and skinfolds as measures of body fat distribution. American Journal of Physical Anthropology, 72(4), 437-439.

Nieman, K., Cademartiri, F., Lemos, P. A., Raaijmakers, R., Pattynama, P. M. T., \& de Feyter, P. J. (2002). Reliable noninvasive coronary angiography with fast submillimeter multislice spiral computed tomography. Journal of the American Heart Association, 106(16), 2051-2054.

Nigg, B. M. \& Liu, W. (1999). The effect of muscle stiffness and damping on simulated impact force peaks during running. Journal of Biomechanics, 32(8), 849-856.

Nordhamn, K., Södergren, E., Olson, E., Karlström, B., Bessby, B., \& Berglund, L., (2000). Reliability of anthropometric measurements in overweight and lean subjects: consequences for correlations between anthropometric and other variables. International Journal of Obesity, 24(5), 652-657.

Norusis, M. J. (2005). SPSS 13.0 guide to data analysis. Upper Saddle River, NJ: Prentice Hall Inc.

Pain M. T. G. \& Challis, J. H. (2002). Soft tissue motion during impacts: their potential contributions to energy dissipation. Journal of Applied Biomechanics, 18(3), 231242.

Pain M. T. G. \& Challis, J. H. (2004). Wobbling mass influence on impact ground reaction forces: a simulation model sensitivity analysis. Journal of Applied Biomechanics, 20, 309-316.

Pain, M. T. G. \& Challis, J. H. (2006). The influence of soft tissue movement on ground reaction forces, joint torques and joint reaction forces in drop landings. Journal of Biomechanics, 39(1), 119-124. 
Perini, T. A., de Oliveira, G. L., dos Santos Ornellas, J., \& de Oliveira, F. P. (2005). Technical error of measurement in anthropometry. Revista Brasileira de Medicina do Esporte, 11(1), 86-90.

Poehlman, E. T., Toth, M. J., \& Gardner, A. W. (1995). Changes in energy balance and body composition at menopause: a controlled longitudinal study. Annals of Internal Medicine, 123(9), 673-675.

Pollock, M. L., Hickman, T., Kendrick, Z., Jackson, A., Linnerud, A. C., \& Dawson, G. (1976). Prediction of body density in young and middle-aged men. Journal of Applied Physiology, 40(3), 300-304.

Potvin, J. R., Chiang, J., Mckean, C., \& Stephens, A. (2000), A psychophysical study to determine acceptable limits for repetitive hand impact severity during automotive trim installation. International Journal of Industrial Ergonomics, 26(6), 625-637.

Prior, B. M., Cureton, K. J., Modlesky, C. M., Evans, E. M., Sloniger, M. A., Saunders, M., \& Lewis, R. D. (1997). In vivo validation of whole body composition estimates from dual-energy x-ray absorptiometry. Journal of Applied Physiology, 83(2), 623630 .

Querido, D. (1998). A preliminary investigation into postmortem changes in skinfold impedance during early postmortem period in rats. Forensic Science International, 96(2-3), 107-114.

Reilly, J. J., Methven, E., McDowell, Z. C., Haching, B., Alexander, D., Stewart, L., \& Kelnar, C. J. H. (2003). Health consequences of obesity. Archives of disease in Childehood, 88(9), 748-752.

Ross, R. (1996). Magnetic resonance imaging provides new insights into the characterization of adipose and lean tissue distribution. Canadian journal of physiology and pharmacology, 74(6), 778-785.

Salamone, L. M., Fuerst, T., Visser, M., Kern, M., Lang, T., Dockrell, M., Cauley, J. A., Nevitt, M., Tylavsky, F., \& Lohman, T. G. (2000). Measurement of fat mass using DEXA: a validation study in elderly adults. Journal of Applied Physiology, 89(1), 345-352.

Sartoris, D. J., \& Resnick, D. (1987). MR imaging of the musculoskeletal system: current and future status. American Journal of Roentgenology, 149(3), 457-467.

Salathé, E. P., Jr., Arangio, G. A., \& Salathé, E. P. (1990). The foot as a shock absorber. Journal of Biomechanics, 23(7), 655-659.

Sherker, S. \& Cassell, E. (1999). Preventing in-line skating injuries. Sports Medicine, 28(5), 325-335. 
Stevens, J. P. (2002). Applied multivariate statistics for the social sciences $\left(4^{\text {th }} \mathrm{ed}\right)$. Hillsdale, NJ: Lawrence Erlbaum Associates.

Sun, S. S., Chumlea, W. C., Heymsfield, S. B., Lukaski, H. C., Schoeller, D., Friedl, K., Kuczmarski, J., Flegal, K, M., Johnson, C. L., \& Hubbard V. S. (2003).

Development of bioelectrical impedance analysis prediction equations for body composition with the use of a model for use in epidemiologic surveys. The American Journal of Clinical Nutrition, 77(2), 331-340.

Tabachnick, B. G., \& Fidell, L. S. (2001). Using multivariate statistics (4th ed). Needman Heights, MA: Allyn and Bacon.

Tan, J.-S., Eng, J. J., Robinovitch, S. N., \& Warnick, B. (2006). Journal of Biomechanics, $39(10), 1804-1811$.

Todd, T. W. \& Lindala, A. (1928). Thickness of the subcutaneous tissues in the living and the dead. The American Journal of Anatomy, 41(2),153-196.

United States Nuclear Regulatory Commission (2005). Retrieved February 7, 2007, http://www.nrc.gov/what-we-do/radiation/affect.html

Van Loan, M. D. (1998). Is dual-energy x-ray absorptiometry ready for prime time $\mathrm{n}$ the clinical evaluation of body composition? The American Journal of Clinical Nutrition, 68(6), 1155-1156.

Van Marken Lichtenbelt, W. D., Westerterp, K. R., Wouters, L., \& Luijendijk, S. C. M. (1994). Validation of bioelectrical-impedance measurements as a method to estimate body-water compartments. The American Journal of Clinical Nutrition, $60(2), 159-166$.

Visser, M., Fuerst, T., Lang, T., Salamone, L., \& Harris, T. B. (1999). Validity of fanbeam dual-energy x-ray absorptiometry for measuring fat-free mass and leg muscle mass. Journal of Applied Physiology, 87(4), 1513-1520.

Wang, Z., Zhu, S., Wang, J., Pierson R. N. Jr., \& Heymsfield, S. B. (2003). Whole-body skeletal muscle mass: development and validation of total-body potassium prediction models. The American Journal of Clinical Nutrition, 77(1), 76-82.

Wellens, R., Chumlea, W. C., Guo, S., Roche, A. F., Reo, N. V., \& Siervogel, R. M. (1994). Body composition in whit adults by dual-energy X-ray absorptiometry, densitometry, and total body water. American Journal of Clinical Nutrition,59(3), $547-555$.

Wilmore, J. H., \& Behnke, A. R. (1970). An anthropometric estimation of body density and lean body weight in young women. The American Journal of Clinical Nutrition, 23(3), 267-274. 
Womersley, J., \& Durnin, J. V. G. A. ( 1977). A comparison of the skinfold method with extent of 'overweight' and various weight-height relationships in the assessment of obesity. British Journal of Nutrition, 38(2), 271-284.

Yamaguchi, H., Yamauchi, H., Yamada, T., Ariyoshi, T., Ailawa, H., \& Kato, Y. (2001). Diagnosity validity of computed tomography for mediastinitis after cardiac surgery. Annals of Thoracic and Cardiovascular Surgery, 7(2), 94-98.

Yue, Z. \& Mester, J. (2002). A model analysis of internal loads, energetics, and effects of wobbling mass during the whole-body vibration. Journal of Biomechanics, 35(5), 639-647. 


\section{Vita Auctoris}

NAME

PLACE OF BIRTH

YEAR OF BIRTH

EDUCATION
Katherine L. Arthurs

Simcoe, Ontario

1982

Valley Heights Secondary School, Walsingham, 1996- 2001

Trinity Western University, Langley, British Columbia 2001 - 2002 BHK, year 1

University of Windsor, Windsor, Ontario $2002-2005$ BHK, years $2-4$

University of Windsor, Windsor, Ontario 2005 - 2007 MHK 